\title{
Selection of Potential Sites for Sustainable Development of Solar Photovoltaic Plants in Northeastern Brazil Using GIS and Multi-Criteria Analysis
}

\author{
Márcia Macedo ${ }^{1}$, Marlos Macedo ${ }^{2}$, Manoel Marinho² \& Emilia Kohlman Rabbani ${ }^{1}$ \\ ${ }^{1}$ Post-Graduate Program in System Engineering, UPE, Pernambuco, Brazil \\ ${ }^{2}$ Post-Graduate Program in System Engineering, UPE, Pernambuco, Brazil \\ Correspondence: Márcia Macedo, Departament of Civil Engineering, Polytechnic School of Pernambuco, Recife, \\ Pernambuco, Brazil. E-mail: marcia.macedo@upe.br
}

Received: March 8, $2021 \quad$ Accepted: April 12, $2021 \quad$ Online Published: April 20, 2021

doi:10.5539/jms.v11n1p147 URL: https://doi.org/10.5539/jms.v11n1p147

\begin{abstract}
Brazil has one of the highest percentages of solar radiation in the world and which it is a favorable condition to generate electricity using solar photovoltaic systems. The construction of photovoltaic plants depends on the site selection that influences the electricity generation capacity and the socio-economic benefits that can be derived from it in the future. This article proposes to combine Spatial analysis that involves the acquisition and management of spatial data using a Geographic Information System (GIS), and the fuzzy multi-criteria AHP-TOPSIS model to identify potential locations for the installation of solar photovoltaic systems in the northeastern region of Brazil, State of Pernambuco. The combination of GIS and fuzzy AHP-TOPSIS offers the user the possibility of assigning merit categories to the mapping according to multiple assessment criteria. The GIS include factors of the restrictions and criteria. The restrictions are inserted into the GIS using layers defined from current legislation (urban areas, undeveloped land, community sites, infrastructure, etc.), which reduce the study area by eliminating zones in which PV installation is not permitted. The results show that 22 and $40 \%$ of the area of the state of Pernambuco has the very high and high potential, respectively, for the implantation of PV.
\end{abstract}

Keywords: photovoltaic solar energy, GIS, multi-criteria decision making, fuzzy logic, AHP-TOPSIS

\section{Introduction}

A country's economic and social development is directly linked to its energy production. The more a country develops, the greater its need for energy, and these costs will directly impact its economy. Because of growing concern for the environment due to the use of fossil fuels since the industrial revolution, renewable sources have begun to play an important role in the diversification of the global energy matrix, contributing to sustainable development.

Brazil is among the 10 largest energy producers in the world, according to the International Energy Agency (WEO, 2018). Its national energy matrix is diversified, however, with more than half being composed of hydroelectric plants (ABSOLAR, 2019). Because it is highly dependent on rainfall, the cost of energy generation increases during the dry season, as thermoelectric plants come on line, with much higher operating costs, directly impacting the cost to consumers.

A photovoltaic system is the most direct way to convert energy from solar radiation into electricity. Photovoltaic systems offer an alternative to traditional generation systems for low power applications in areas with access to electricity, which can be connected to medium and low voltage networks. Although still only making up a small percentage of Brazilian energy production, the reduction in costs generated by the advancement of technology, large-scale production, and new financing practices has led to rapid growth of the solar energy sector, already surpassing nuclear energy in installed capacity (ABSOLAR, 2019). In Latin America, Brazil gained prominence in 2017, when it installed more than $1 \mathrm{GW}$ of solar energy production for the first time, mainly from systems awarded in public auctions.

The northeast region of Brazil has become one of the principal regions for the implantation of photovoltaic solar power plants. Many factors are responsible for this trend, not least of which is the fact that the region has one of 
the highest levels of potential solar radiation in the country. Specifically, in the state of Pernambuco, the annual average of global radiation exceeds $5 \mathrm{kWh} / \mathrm{m} 2$ per day over most of its territory (Macedo et al., 2015). Because of these excellent climatic characteristics, this territory has become attractive for the implantation of photovoltaic solar plants (PV). Pernambuco also has Law No. 14,090, of 17 June 2010, which establishes goals for mitigating greenhouse gas emissions, encourages sustainable construction, and requires projects with a high environmental impact to inventory their greenhouse gases emitted. In order to obtain higher returns at their facilities, developers and investors need to use decision support models and methods that make it possible to maximize PV efficiency.

The analysis of the criteria that affect resource availability is an important part of the solar energy planning process. The criteria used in selecting the location for new plants may include: energy production, orography (slopes and orientation), environment (land use, land cover, erosion, flood risk, accessibility, and visual impact), distances (from roads, from energy substations, and from urban areas), financial, and climatic (solar radiation, temperature, dust, and wind). In fact, selecting a PV site is a complicated decision-making process, because the site is required to be climatically and geographically satisfactory, and must simultaneously have the greatest possible generation potential (Macedo et al., 2015). Therefore, it is essential that technological, economic, and environmental aspects be considered, as it is a complex process that needs complete information on a wide range of criteria that impact deciding-making regarding the available areas (Tahri, Hakdaoui, \& Maanan, 2015). Multi-criteria decision analysis (MCDA) approaches are the most appropriate means to provide decision support.

However, according to the reviewed literature, there are some gaps in knowledge associated with photovoltaic solar plant site selection. The number of variables is limited in the literature and does not distinguish exclusionary aspects that make solar plant projects unfeasible like areas of risk or legal exclusion, from those aspects that limit or condition the activity like slope, orientation, temperature, radiation, etc.). In other words, the criteria considered may not identify the most suitable areas (Yushchenko et al., 2018).

In this context, Geographic Information Systems (GISs) are suitable tools for analyzing and visualizing spatial information, which have been used in energy applications to assess resources and plan infrastructure. GIS can be used to spatially solve problems related to data integration and resource management such as analytical and spatial modeling, spatial display, and reporting (Yushchenko et al., 2018). With the ability to manipulate data in digital models (raster and vector) GIS offers a collection of procedures, techniques, and algorithms to structure data to instantiate decision-making problems that deal with the design, evaluation, and prioritization of alternative decisions (Macedo et al., 2020).

Various decision-making techniques have been developed in previous studies to select the location of solar plants and other energy projects based on geographic information systems (GIS) and spatial analyses (Yang et al., 2018). For example, Lee et al. (2014) applied the MCDA method based on the Analytic Hierarchy Process (AHP) to the selection of wind farm installation strategies. Janke (2010) studied MCDA for solar and wind farms using GIS. Charabi and Gastli (2011) studied the location of solar farms using GIS and fuzzy logic. Arán-Carrión et al. (2008) and Tahri, Hakdaoui and Maanan (2015) applied Geographic Information Systems (GIS) and AHP to assess solar park locations. Merrouni, Mezrhab and Mezrhab (2016) developed a goal programming model to select appropriate locations for different types of renewable energy installations. Sánchez-Lozano, García-Cascales and Lamata (2016) evaluated seven regions of hybrid wind/solar power stations via ELECTRE- II and found the result to have better correction than results from related studies. Maleki, Hizam and Gomes (2017) conducted a multi-criteria assessment of photovoltaic technologies using the TOPSIS and AHP methods. In northeastern Brazil, Tiba et al. (2014), Azevêdo, Candeias and Tiba (2017) and da Ponte, Calili and Souza (2021) analyzed the development of a management and planning system on a GIS platform and multi-criteria analyses for renewable energy source administrators, planners, or consultants.

For the current study, a combined approach using GIS and the fuzzy AHP-TOPSIS method is described in order to classify the possible locations for photovoltaic parks in the northeastern Brazilian state of Pernambuco, into categories of merit according to the assessment criteria. First, certain areas are excluded, simplifying the subsequent analysis and allowing for more information to be included. After that, to carry out more detailed analyses, the aspects to be considered when selecting locations are classified into criteria and sub-criteria.

This two-stage approach combines criteria, which include solar radiation, local physical terrain, environment, climate, location, distance from roads and transmission lines, technology employed, and deployment costs. GIS data (solar radiation time series, digital elevation model (DEM), ground cover, and temperature) were used as additional input parameters. The objective of this study is to provide a methodology that identifies locations with potential for photovoltaic generation, and thereby supports the development of new photovoltaic plants. The methodology applied for Pernambuco, in the northeast of Brazil, considered the installation of 1 to $5 \mathrm{MW}$ 
photovoltaic plants. The results of this study can help find potential areas for the development of solar plants in any country.

\subsection{Future Perspectives for Solar Energy in Brazil}

The need for complementarity in the Brazilian electrical system, currently heavily reliant on hydroelectric sources, along with the fact that sunlight is clean and renewable, with no GHG emissions, should lead to increased use of solar energy in the Brazilian electrical energy matrix over the next few years, and contribute to a deceleration of global warming. In light of growing efforts to improve existing technologies to increase the efficiency of solar modules and considerably reduce production costs, future prospects for the use of solar energy are positive, especially for electrical generation using photovoltaic modules (ABSOLAR, 2019).

The use of photovoltaic solar energy is appropriate for remote or hard-to-reach places, because its small scale installation does not require large investments in transmission lines. This technology has the potential to replace diesel or oil fired generators that currently supply these isolated communities.

In Brazil, the growth of photovoltaic electrical generation has been favored and pushed forward by ANEEL (Agência Nacional de Energia Elétrica), through Normative Resolution 482 of 17 April 2012, whose revision process should be completed by the end of 2021 (ANEEL, 2020). This regulation allows for the micro and mini-generation of electricity from renewable energy sources with distributed generation systems, connected to low voltage electrical networks. In other words, it allows residential, commercial, and business customers to install photovoltaic panels and deduct this micro-generation from their energy bills. In this way, it will become possible for consumers to invest in solar power generation systems that can be connected to the transmission grid, and not just for their own consumption. Consumers will tend to become energy suppliers, as well.

The Brazilian government's willingness to organize exclusive auctions for solar energy should also favor the acceleration of demand for solar energy consumption. The volume of energy negotiated at auction would work as a guarantee of minimum demand to meet the scale requirements for the local installation of production units, which, in most cases, would be photovoltaic modules.

\section{Materials and Methods}

The methodology developed in this study is made up of five steps, described in the flowchart shown in Figure 1. In the first step, the study area was defined. In Step 2, the criteria used to evaluate the suitability of a site for a PVP were identified through the analysis of specialists and through bibliographic analysis. These factors included site characteristics, territorial restrictions, and areas of exclusion. In Step 3, the variables to be included in the GIS model were identified and the data collection activities were carried out. For the GIS modeling, in Step 4, MDCA techniques were applied to the input data set. This phase included the selection and application of weighting to criteria and subcriteria. Finally, in Step 5, a map with the potential PVP locations was produced and analyzed.

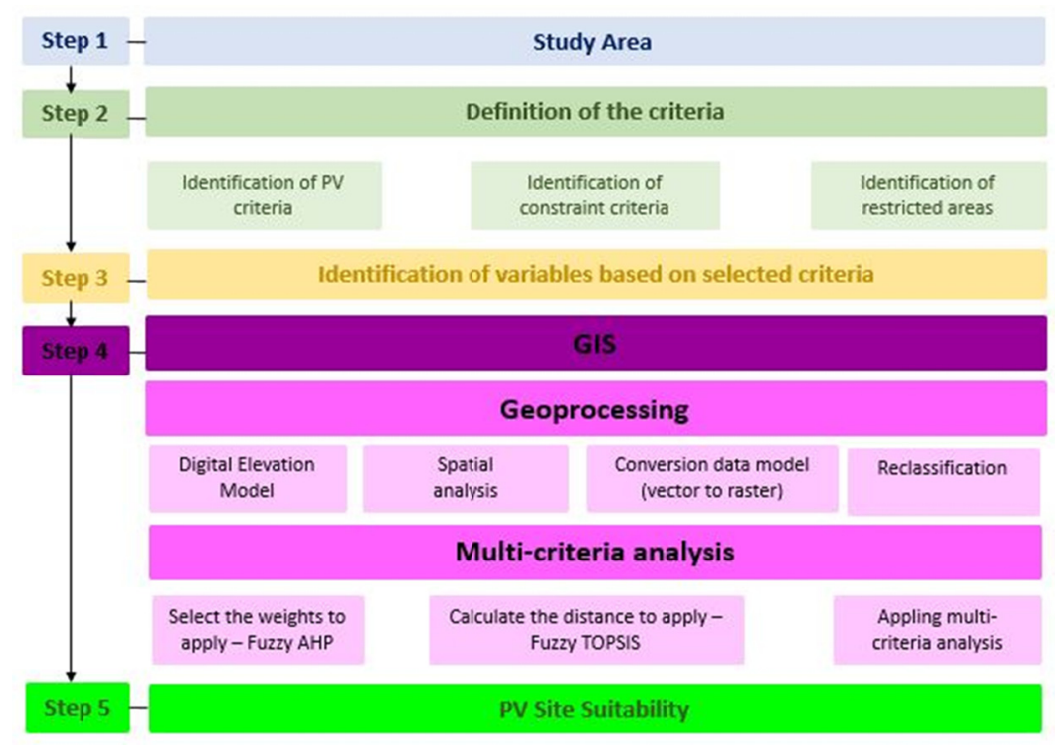

Figure 1. Methodology for selecting suitable PVP locations 


\subsection{Step 1-Study Area}

According to the IBGE (Brazilian Institute of Geography and Statistics), Pernambuco is located in the Central East part of Brazil's Northeast Region, between 7.150 and 9.270 south latitude and 34.000 and 48.190 west longitude. It has a territory covering $98,149.119 \mathrm{~km}^{2}$, and is bordered by the Atlantic Ocean and the States of Paraíba, Ceará, Piauí, Bahia, and Alagoas. The state also includes the archipelago of Fernando de Noronha, located $545 \mathrm{~km}$ from Recife (the capital of Pernambuco).

The Gross Domestic Product (GDP) of the northeast region, over the past year, grew at a rate only half that of Brazil's average. In 2018, the northeastern GDP grew only $0.6 \%$, while Brazil's rose $1.1 \%$. With a real average monthly worker income of US\$ 385.00 , Northeast Brazil still relies heavily on the federal public sector for investments in infrastructure (IBGE, 2019). On average, electricity costs represent 10\% of low-income household income and the use of solar energy could reduce this amount by $87 \%$. Rural residents and businesses invested heavily in solar energy source, increasing their generating capacity. This is because, especially solar energy, reduce costs, including maintenance.

According to the regional division of Brazil into geographical mesoregions, Pernambuco contains five well-defined environments: the Recife Metropolitan Area, the Forest Zone, the Agreste, the Sertão, and the Sn Francisco Basin. These environments are shown in Figure 2.

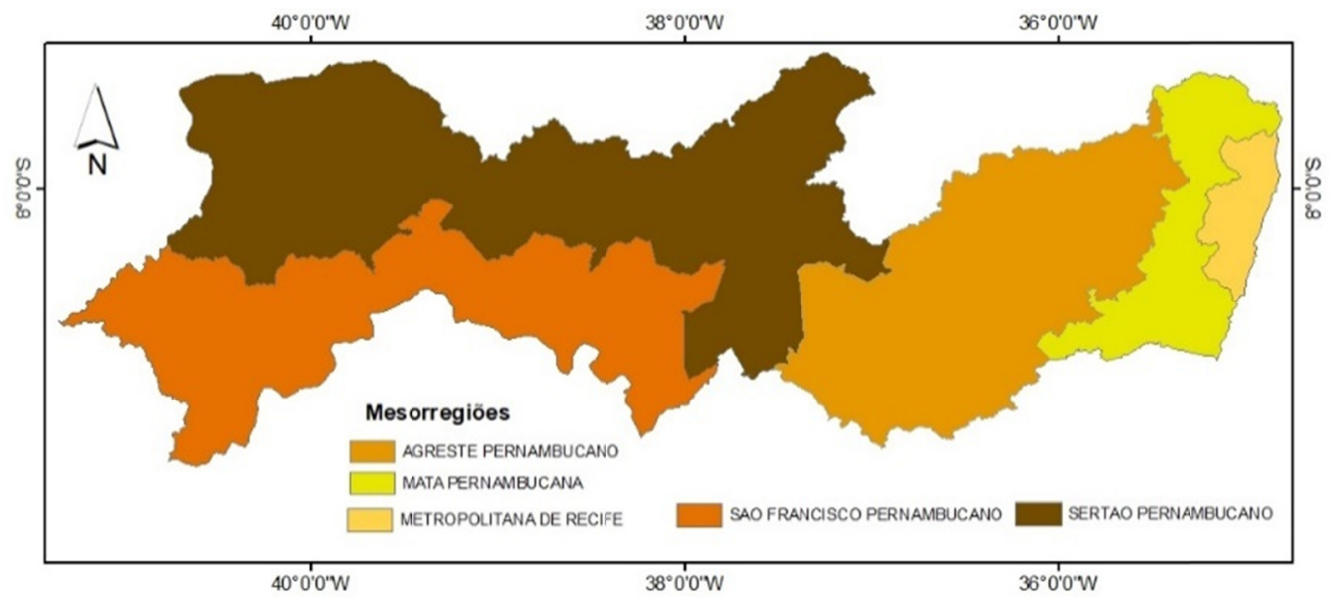

Figure 2. Study area

\subsubsection{Criteria for Selecting Sites for the Installation of Photovoltaic Solar Plants}

There are a number of different criteria to be considered when installing photovoltaic power plants (PVP), such as accessibility (Janke, 2010; Charabi \& Gastli, 2011), orientation and slope (Charabi \& Gastli, 2011; Sánchez-Lozano, García-Cascales, \& Lamata, 2016), ground cover (Charabi \& Gastli, 2011; Sánchez-Lozano, García-Cascales, \& Lamata, 2016), location and inclination of panels (Oliveira \& Gómez- Malagón, 2018), and land use (Sánchez-Lozano, García-Cascales, \& Lamata, 2016). This makes solar energy planning increasingly complex. The criteria can be grouped into three categories: environmental, social, and technical-economic.

The amount of solar radiation received at the earth's surface determines the amount of solar energy available to be converted into electricity. If all criteria other than solar radiation are good, the site will not qualify as a good location to install a PVP. The US National Renewable Energy Laboratory (NREL) classified the level of solar radiation into four categories, including: moderate (less than $4 \mathrm{kWh} / \mathrm{m} 2 /$ day), good ( $4-5 \mathrm{kWh} / \mathrm{m} 2 /$ day), very good (5-6 kWh/m2/day) and excellent ( $>6 \mathrm{kWh} / \mathrm{m} 2 /$ day) (Phuangpornpitak \& Tia, 2016). In Pernambuco, the maximum DNI value is $5.8 \mathrm{kWh} / \mathrm{m} 2 /$ day (annual average daily value) according to currently available information, published by a competent government agency (ABSOLAR, 2019).

Forested areas are not appropriate for PVP installation, due to the shade cast by trees on collectors, photovoltaic modules, and other devices. In Pernambuco, $83 \%$ of the territory is covered by the Caatinga biome. Because it is the only exclusively Brazilian biome, with much of its biological heritage not found anywhere else on the planet, it must be preserved. Its name stems from the whitish landscape presented by vegetation during the dry period, when most plants lose their leaves and the trunks become whitish and dry (Macedo et al., 2015). There are several indices used to obtain vegetation information for remote sensing images, usually by the ratio of intensity 
of a near infrared (NIR) band compared to a red band. This takes advantage of the high reflectance of vegetation in the NIR spectral range and the high pigment absorption of red light (Tahri, Hakdaoui, \& Maanan, 2015). The Normalized Difference Vegetation Index (NDVI) is the best indicative factor for the state of plant growth and the spatial distribution of vegetation, which is linearly related to the vegetation distribution density.

Other areas with restrictions must be considered. These areas include bodies of water, ecologically sensitive areas, wildlife conservation areas, floodplains, towns and cities, roads, railways, and steep hillside areas. Photovoltaic modules contain some toxic and dangerous material components that must not be disposed of in the environment, for example, waste produced over the long term for which there is still no suitable destination (Zekai, 2014). Therefore, solar plants should be installed at a safe distance from sensitive areas. Large-scale installations of photovoltaic systems can also damage areas of land with potential for agriculture (Zekai, 2014). On the other hand, the protection of land with potential for agriculture is a principal environmental objective. Based on Aydin, Kentel and Duzgun (2013) agricultural areas should be excluded from being selected for PVP installation.

Slope is a topographic feature that can strongly affect project costs, and which therefore plays an important role in the selection of a suitable location for a solar power plant. On steep terrain, panels can create shade on neighboring panels, reducing energy conversion efficiency. It is also easier to set up the infrastructure on level ground, reducing overall construction costs. The ideal slope for the module that depends on latitude (for example, in Pernambuco, at latitude $9^{\circ}$ south, this can be found between $1^{\circ}$ and $5^{\circ}$, with $10^{\circ}$ being recommended to avoid the formation of dust layers that can absorb part of the incident radiation). The orientation of the panel is another factor that affects the output of the PV modules. The ideal orientation of the module is always towards the north in the southern hemisphere (Oliveira \& Gómez- Malagón, 2018).

Altitude and temperature are also factors that affect the normal functioning of solar panels and the production of solar energy. High altitudes increase the difficulty of building photovoltaic plants and can affect transmission facilities, however, the highest density areas of solar energy occur in high-altitude desert areas. Altitudes above $5800 \mathrm{~m}$ are not recommended, although this depends on the study area (Pinto, Amaral, \& Janissek, 2016). According to Skoplaki and Palyvos (2008) areas with an average temperature below $10^{\circ} \mathrm{C}$ or above $20^{\circ} \mathrm{C}$ should be excluded. The c-Si photovoltaic modules lose energy as temperature increases above the standard test conditions $\left(25^{\circ} \mathrm{C}\right)$ at the rate of 0.5 and $0.6 \% /{ }^{\circ} \mathrm{C}$ and therefore, exceeding the critical limit of $25^{\circ} \mathrm{C}$ is not recommended. With regard to moisture, the greater the amount of relative humidity in an area, the greater the absorption of short-wave solar radiation, which decreases the total amount of incident solar irradiation usable by the solar panel (Pinto, Amaral, \& Janissek, 2016).

\subsection{Step 2-Criteria Definition}

The computer programs used were ArcGIS 10.3 (ESRI) and QGis (OSGeo 4W). Various cartographic sources were used, including maps from the Brazilian Institute of Geography and Statistics (IBGE), the National Department of Traffic Infrastructure (DNIT), the Brazilian Agricultural Research Corporation (Embrapa), the Pernambuco State Planning and Research Agency (Condepe/Fidem), and the National Institute for Colonization and Agrarian Reform (Incra). The solar radiation maps were obtained from The National Solar Radiation Database-NSRDB (Sengupta et al., 2018) and temperatures were obtained from Global climate and weather data (WorldClim).

\subsection{Step 3-Criteria Selection}

Based on the literature review, all of the information was synthesized, criteria were chosen, and a preliminary list was defined. This list of criteria was sent to a group of experts in photovoltaic solar plants for approval. Based on their assessment, the list of criteria for the selection of photovoltaic plant sites was established. The criteria were separated into positive and negative indicators or restrictions. The restrictions to be inserted in the GIS are obtained from the regional public administrative bodies. These indicators constitute the technical and environmental restrictions of the study area (Table 1).

After excluding the restricted areas, positive indicators were adapted to assess the suitability of locations for a photovoltaic solar plant. This was based on five criteria (climate, topography, environment, location, and economic) and included ten factors (direct solar radiation, temperature, slope, orientation, land use, NDVI, distance to transmission lines, distance to water resources, distance to main roads, distance to urban areas, and project cost). Table 5 presents all of the evaluations. 
Table 1. Negative indicators or restrictions

\begin{tabular}{lll}
\hline Criteria & Sub-Criteria & Negative Indicator \\
\hline Environmental & Land Use & Conservation Units \\
& Remnants of the Atlantic Forest \\
& Indigenous Territories \\
& Quilombo Territories \\
& Areas of High Agricultural Potential \\
& Urban and Urban Expansion Areas \\
& Water Bodies \\
& Flood risk \\
& Landslide risk \\
\hline
\end{tabular}

\subsection{Step 4-GIS}

Figure 3 displays a flow chart showing the GIS-based methodology used throughout the process of site selection. It shows the steps performed to create the layers, implement the criteria weighting, and select the locations appropriate for PVPs.

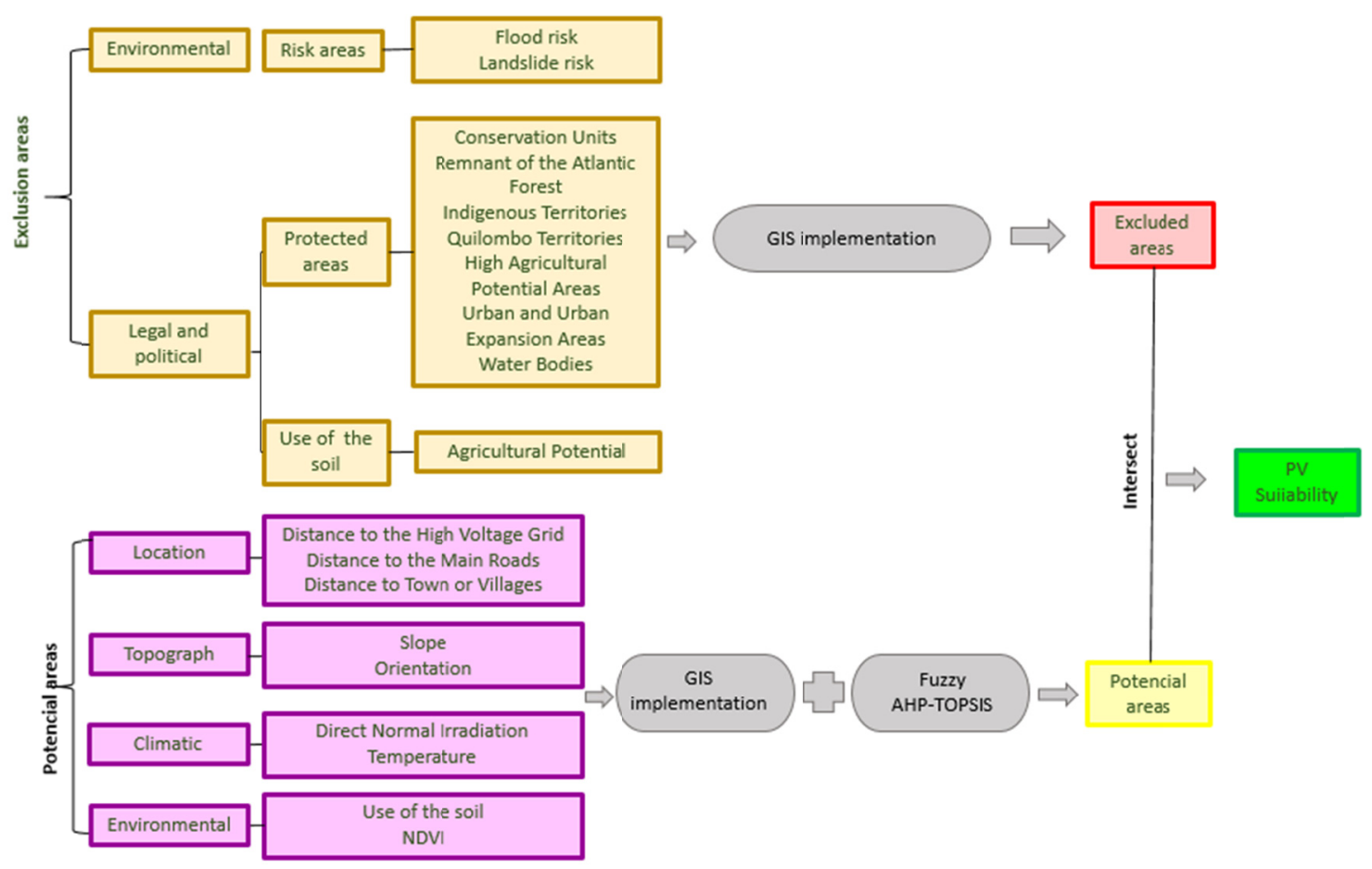

Figure 3. Proposed Gis method

\subsubsection{Geoprocessing}

This stage consists of the systematization of existing information, the analysis of spatial data quality, and the preparation and editing of the base layers of the database. The spatial data was standardized using SIRGAS2000 as the Geodetic Reference System and the Equidistant Conical Cartographic Projection for the raster and vector data models.

Each criterion selected, other than the project, was modeled as a layer (sublayers) and drawn as a map (in raster format) in a GIS environment, with a spatial resolution of $20 \mathrm{~m}$. The data originally in vector format was converted to raster. The set of thematic maps was produced from the Spatial Database (SDB) built specifically for this study, with the aid of ArcGIS 10.3 mapping software.

Protected areas (non-urban protected areas and urban soils) or areas with restrictions due to hazards were introduced in the first layers (12 restrictions). These were superimposed to obtain a map of restricted areas, 
which were then eliminated from the total area of the study. From this, non-excluded areas were obtained. Environmental and technical restrictions were then introduced (4 restrictions). All of these restriction layers were also modeled and their values multiplied to form the final restriction layer. Locations with a zero value for each constraint layer would also be zero in the final constraint layer. For example, a location with a high risk of flooding, completely inadequate for a solar plant (the fuzzy association value is zero), would also appear as completely inadequate in the final restriction layer, with a fuzzy association value of zero, even if the fuzzy association values for all other layers were one. Locations with a value of one in all sublayers, also have a value of one in the final constraint layer.

After this, the criteria layers (environmental, topographic, climatic, and location) were reclassified into five classes of intervals and overlaps. Finally, this layer was crossed with the non-excluded areas layer to determine the areas having the highest potential for solar plants.

\subsubsection{Multi-Criteria Analysis-Fuzzy AHP-TOPSIS}

With the AHP method, a problem is structured into hierarchical levels where the criteria and sub-criteria are defined in order to assess technological options and where expert judgment is required to define the importance of each criterion and sub-criterion through peer-to-peer comparison, according to the preference established between them. The importance of one attribute over another are represented by fuzzy triangular numbers. These numbers are calculated according to expert judgment using linguistic terms based on the Saaty scale in 9 levels (Table 2).

Table 2. Fundamental Saaty scale

\begin{tabular}{lll}
\hline Numerical Scale & Verbal Scale & Explanation \\
\hline 1 & Both elements are of equal importance & Both elements contribute to the property equally \\
3 & Moderate importance of one element over the other & Experience and opinion favor one element over the other \\
5 & Strong importance of one element over the other & One element is strongly favored \\
7 & Very strong importance of one element over the other & One element is very strongly favored over the other \\
9 & Extreme importance of one element over the other & One element is favored with at least an order of \\
& & magnitude difference \\
$2,4,6,8$ & Intermediate values between adjacent opinions & Used as consensus values between opinions \\
0.1 increments & Intermediate values at the finest gradation of 0.1 & Used for finer grades of opinions \\
\hline
\end{tabular}

The AHP-TOPSIS fuzzy method uses the fuzzification process, that is, by definition, the triangular fuzzy number $(1,1,1)$ is used when two attributes are considered equally important (have a level of importance equal to 1 on the Saaty scale) (Trindade, 2016; Şengül, 2014; Arce, 2015; Kaya \& Kahraman, 2010).

To represent other levels of importance as a triangular fuzzy number $\left(a_{1}, a_{2}, a_{3}\right)$, all judgments are counted in each paired comparison and simple arithmetic operations are performed to define the minimum $\left(\mathrm{a}_{1}\right)$, intermediate $\left(a_{2}\right)$ points, and maximum $\left(a_{3}\right)$. From the expert judgment, the matrices for comparing the criteria and subcriteria are built (Figure 4):

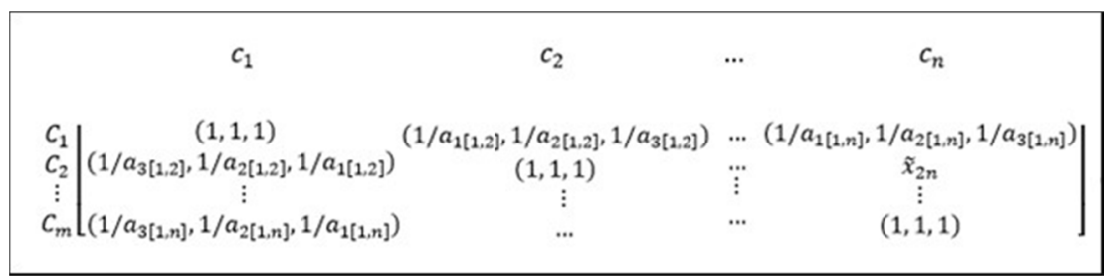

Figure 4. Pairwise comparison matrix

Consistency analysis of the fuzzy pairwise comparison matrices with the consistency index (CI) can be performed using the classic AHP method, because, when the comparison of the crisp matrix (fixed real values) $A$ is consistent, then the fuzzy comparison matrix Ã will also be consistent.

The consistency ratio (CR) is used to estimate the consistency of the paired comparisons. When $\mathrm{RC} \leq 0.10$, the consistency is accepted, otherwise, it is necessary to review the comparison matrix (Equation 1).

$$
\mathrm{CI}=\mathrm{IC} / \mathrm{R}
$$


The random consistency index (RI) was determined empirically considering a randomly generated sample of 500 positive reciprocal matrices (Phuangpornpitak \& Tia, 2016). The values attributed to IR by Saaty, according to the matrix order (n), are shown in Table 3.

Table 3. Empirical values for the random consistency index

\begin{tabular}{|c|c|c|c|c|c|c|c|c|c|c|c|c|c|c|}
\hline 1 & 2 & 3 & 4 & 5 & 6 & 7 & 8 & 9 & 10 & 11 & 12 & 13 & 14 & 15 \\
\hline 0.00 & 0.00 & 0.58 & 0.90 & 1.12 & 1.24 & 1.32 & 1.41 & 1.45 & 1.49 & 1.51 & 1.48 & 1.56 & 1.57 & 1.59 \\
\hline
\end{tabular}

The consistency index for the pairwise comparison matrix (CI) is calculated from the relationship between the size of the matrix (n) and its largest eigenvalue $(\lambda \max )$, as shown in Equation 2:

$$
\mathrm{CI}=(\lambda \max -\mathrm{n}) /(\mathrm{n}-1)
$$

Criteria weightings were determined by pairwise comparison between criteria. A total of (n-1) comparisons were required. According to Sánchez-Lozano, García-Cascales and Lamata (2016) the weightings can be obtained using Equation 3:

$$
\left(\mathrm{w}_{\mathrm{C}_{\mathrm{ia}}}, \mathrm{w}_{\mathrm{C}_{\mathrm{ib}}}, \mathrm{w}_{\mathrm{C}_{\mathrm{ic}}}\right)=\left[\frac{\mathrm{C}_{\mathrm{ia}}}{\sum_{\mathrm{i}=1}^{\mathrm{n}} \mathrm{C}_{\mathrm{ic}}}, \frac{\mathrm{C}_{\mathrm{ib}}}{\sum_{\mathrm{i}=1}^{\mathrm{n}} \mathrm{C}_{\mathrm{ib}}}, \frac{\mathrm{C}_{\mathrm{ic}}}{\sum_{\mathrm{i}=1}^{\mathrm{n}} \mathrm{C}_{\mathrm{ia}}}\right]
$$

Where: wci represents the weighting of the criteria by specialist $i$, and $i=1,2,3$ and ci are the comparisons between the criteria for fuzzy pairs.

In the Fuzzy-TOPSIS phase, the values for each criterion and sub-criterion are provided by decision makers, from the evaluation of each technology. For this vague and subjective classification, the five-point Likert scale is commonly used, in which each point represents a maturity level, and consequently, each level receives a fuzzy triangular numerical value (Table 4).

Table 4. Linguistic terms and their respective numerical values

\begin{tabular}{ll}
\hline Description & Maturity Level \\
\hline Very Low (VL) & 1 \\
Low (L) & 2 \\
Moderate (M) & 3 \\
High (H) & 4 \\
Very High (VH) & 5 \\
\hline
\end{tabular}

From the linguistic terms and respective fuzzy values, a decision matrix $\tilde{D}$ is constructed (Figure 5). In matrix $\tilde{D}$, $\mathrm{x}_{\mathrm{ij}}$ represents the value of alternative $\mathrm{A}_{\mathrm{i}}$ with respect to criterion $\mathrm{C}_{\mathrm{j}}, \mathrm{W}=\left[\mathrm{w}_{1}, \mathrm{w}_{2}, \ldots, \mathrm{w}_{10}\right]$ is the weighting vector associated with the criteria, $\mathrm{A}_{\mathrm{m}}$ are the alternatives, and $\mathrm{x}_{\mathrm{mn}}$ are the values determined by the decision makers.

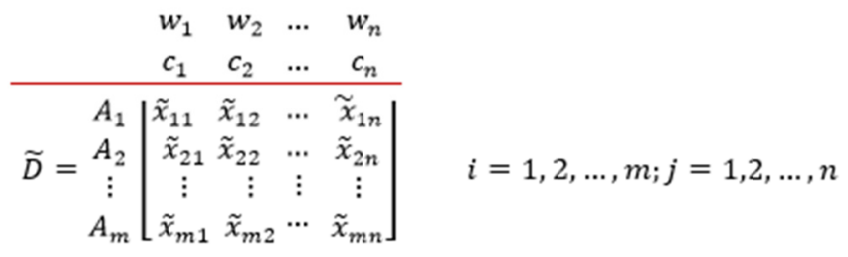

Figure 5. Decision matrix-Fuzzy TOPSIS method

Matrix $\tilde{D}$ is normalized so that the scale is the same for all criteria (Equation 4). The criteria weightings in decision-making problems do not have the same average and not all are equally important. The weighted normalized value $\mathrm{v}_{\mathrm{ij}}$ is calculated by Equation 5 .

$$
\overline{\mathrm{n}}_{\mathrm{ij}}=\frac{\mathrm{x}_{\mathrm{ij}}}{\sqrt{\sum_{\mathrm{i}=1}^{\mathrm{m}}\left(\mathrm{X}_{\mathrm{ij}}\right)^{2}}} \quad \mathrm{j}=1,2, \ldots, \mathrm{n} ; \mathrm{i}=1,2, \ldots, \mathrm{m}
$$




$$
\overline{\mathrm{v}}_{\mathrm{ij}},=\mathrm{w}_{\mathrm{ij}} \otimes \overline{\mathrm{n}}_{\mathrm{ij}} \quad \mathrm{j}=1,2, \ldots, \mathrm{n} ; \mathrm{i}=1,2, \ldots, m
$$

The ideal positive (PIS, A +) and negative (NIS, A-) fuzzy solutions are determined according to Equation 6 and Equation 7, respectively.

$$
\begin{aligned}
\mathrm{A}^{+} & =\left\{\tilde{\mathrm{v}}_{1}^{+}, \tilde{\mathrm{v}}_{2}^{+}, \ldots, \tilde{\mathrm{v}}_{\mathrm{m}}^{+}\right\} \\
\mathrm{A}^{-} & =\left\{\tilde{\mathrm{v}}_{1}^{-}, \tilde{\mathrm{v}}_{2}^{-}, \ldots, \tilde{\mathrm{v}}_{\mathrm{m}}^{-}\right\}
\end{aligned}
$$

Where: $\tilde{\mathrm{v}}_{1}^{+}=(1,1,1)$ and $\tilde{\mathrm{v}}_{1}^{-}=(0,0,0)$.

The distances to PIS (D+) and to NIS (D-) are calculated by Equation 8 and Equation 9, respectively.

$$
\begin{aligned}
& D_{i}^{+}=\sum_{j=1}^{n} d_{v}\left(\bar{v}_{i j}, \tilde{v}_{j}^{+}\right) \\
& D_{i}^{-}=\sum_{j=1}^{n} d_{v}\left(\bar{v}_{i j}, \tilde{v}_{j}^{-}\right)
\end{aligned}
$$

Finally, the $\mathrm{CC}_{\mathrm{i}}$ approximation coefficients are calculated for each of the evaluated alternatives, according to Equation 10. The $\mathrm{CC}_{\mathrm{i}}$ value varies between 0 and 1 . The closer to 1, the higher the priority of the alternative. From this, the final ranking of the alternatives is defined from the $\mathrm{CC}_{\mathrm{i}}$ values.

\section{Results}

$$
\mathrm{CC}_{\mathrm{i}}=\mathrm{D}_{\mathrm{i}}^{-} /\left(\mathrm{D}_{\mathrm{i}}^{+}+\mathrm{D}_{\mathrm{i}}^{-}\right)
$$

This section presents the results of the potential sites for sustainable development of solar photovoltaic plants appropriate to the reality in the State of Pernambuco.

\subsection{Classification of Input Criteria}

The five-point Likert scale was used to classify the sub-criteria. The maturity levels considered were: 1 -very low; 2-low; 3-moderate; 4-high; 5-very high (Table 5). 
Table 5. Classification of criteria and sub-criteria by the Fuzzy AHP-TOPSIS method

\begin{tabular}{|c|c|c|c|c|}
\hline Criteria & Labels & Sub-Criteria & Classes & Grades \\
\hline \multirow[t]{10}{*}{ Climatic } & $\mathrm{C} 1$ & Direct Normal Irradiation & $3.8-4.2$ & 1 \\
\hline & & $(\mathrm{kWh} / \mathrm{m} 2 \cdot$ day $)$ & $4.2-4.6$ & 2 \\
\hline & & & $4.6-5.0$ & 3 \\
\hline & & & $5.0-5.4$ & 4 \\
\hline & & & $5.4-5.8$ & 5 \\
\hline & $\mathrm{C} 2$ & Average Temperature (0C) & $<10$ & 1 \\
\hline & & & $10-15$ & 2 \\
\hline & & & $15-20$ & 3 \\
\hline & & & $20-25$ & 4 \\
\hline & & & $>25$ & 5 \\
\hline \multirow[t]{10}{*}{ Topographic } & $\mathrm{T} 1$ & Slope (\%) & $0-2$ & 5 \\
\hline & & & $2-4$ & 4 \\
\hline & & & $4-6$ & 3 \\
\hline & & & $6-10$ & 2 \\
\hline & & & $>10$ & 1 \\
\hline & $\mathrm{T} 2$ & Orientation (Cardinal points) & Horizontal and South & 1 \\
\hline & & & Southeast and Southwest & 2 \\
\hline & & & East and West & 3 \\
\hline & & & Noertheast and Northwest & 4 \\
\hline & & & North & 5 \\
\hline \multirow[t]{10}{*}{ Environmental } & E1 & Land Use & Regular Agricultural Potential & 5 \\
\hline & & & Regular to Limited Agricultural Potential & 4 \\
\hline & & & Limited Agricultural Potential & 3 \\
\hline & & & Limited to Unfavorable Agricultural Potential & 2 \\
\hline & & & Unfavorable Agricultural Potential & 1 \\
\hline & E2 & NDVI & $<0$ & 5 \\
\hline & & & $0-0.2$ & 4 \\
\hline & & & $0.2-0.4$ & 3 \\
\hline & & & $0.4-0.6$ & 2 \\
\hline & & & $>0.6$ & 1 \\
\hline \multirow[t]{15}{*}{ Location } & L1 & Distance to High Voltage Grid ( $\mathrm{km})$ & $0-5$ & 1 \\
\hline & & & $5-10$ & 2 \\
\hline & & & $10-15$ & 3 \\
\hline & & & $15-20$ & 4 \\
\hline & & & $>20$ & 5 \\
\hline & $\mathrm{L} 2$ & Distance to Main Roads (km) & $0-2.5$ & 1 \\
\hline & & & $2.5-5.0$ & 2 \\
\hline & & & $5.0-10$ & 3 \\
\hline & & & $10-15$ & 4 \\
\hline & & & $>15$ & 5 \\
\hline & L3 & Distance to Town or Villages $(\mathrm{km})$ & $0-10$ & 5 \\
\hline & & & $10-20$ & 4 \\
\hline & & & $20-30$ & 3 \\
\hline & & & $30-40$ & 2 \\
\hline & & & $>40$ & 1 \\
\hline \multirow[t]{5}{*}{ Cost } & $\mathrm{V} 1$ & Investment value/m2 (Reals) & $170-300$ & 1 \\
\hline & & & $300-330$ & 2 \\
\hline & & & $330-350$ & 3 \\
\hline & & & $350-398$ & 4 \\
\hline & & & $398-491$ & 5 \\
\hline
\end{tabular}

The climatic criterion was considered one of the most important in the evaluation of the spatial aptitude for the development of solar projects, and for that reason it has the highest weighted coefficient in this study. Other criteria (topography, environment, and location) were considered to be of lesser importance, as they can be adapted by human intervention on the ground. For the economic criterion, the inverter technology was not considered and the cost of the project was not considered in the analysis, as the criterion presented a consistency ratio of $0.00 \%$ and can be adapted according to available resources. 
In terms of climate, Pernambuco has high levels of direct normal irradiation, ranging from 3.8 to 5.8 $\mathrm{kWh} / \mathrm{m} 2 \cdot$ day, with the highest levels $(5.4-5.8 \mathrm{kWh} / \mathrm{m} 2 \cdot$ day) occuring in the Sertão mesoregion and in isolated areas of the São Francisco mesoregion. The average temperature ranges from 16 to $24^{\circ} \mathrm{C}$. During the summer months, the maximum daily temperatures can reach over $35^{\circ} \mathrm{C}$ and, under these conditions, the efficiency of a photovoltaic solar plant can be significantly affected. Average daily maximum temperatures were recorded in December, in the municipalities of Salgueiro $\left(38^{\circ} \mathrm{C}\right)$, Petrolina $\left(38^{\circ} \mathrm{C}\right)$, Floresta $\left(40.7^{\circ} \mathrm{C}\right)$, Arcoverde $\left(37^{\circ} \mathrm{C}\right)$, and Cabrobó $\left(39.5^{\circ} \mathrm{C}\right)$, in the Sertão, Surubim $\left(36^{\circ} \mathrm{C}\right)$, in the Agreste, and São Lourenço da Mata $\left(35^{\circ} \mathrm{C}\right)$ and Recife $\left(38^{\circ} \mathrm{C}\right)$ in the Recife Metropolitan Area. However, the demand for electricity is expected to increase during that time of year, mainly due to the use of air conditioning. This reinforces the importance of effective planning for the use of solar energy throughout the year. The labels were assigned according to importance, 1 to 5 , from lowest to highest.

The agricultural potential (E1) divides the land into agricultural classes of very low capacity (1) to very high capacity (5). This capacity is seen from the point of view of an ideal location for renewable energy installations, meaning that a field labelled as 1 has a high agricultural potential, while one labeled as 5 is the least suitable for the development of agriculture and the best for the installation of a photovoltaic plant.

A similar procedure was used for the slope criterion. Most of the state varies between smoother slopes ( $0-2 \%$ and 2-4\%) found in the Agreste and Sertão regions, mainly in areas along the banks of the São Francisco River. If an alternative has a low slope $(<2 \%)$, it receives the label 5 and, conversely, if an alternative has a high slope ( $>$ $10 \%$ ), it receives the label 1.

The orientation criterion is defined in degrees (0-360), where north is the best orientation, given a label of 5, and south is the worst orientation, given a label of 1 . In Pernambuco, the best places for the construction of photovoltaic plants are areas with flat and slightly inclined terrain oriented towards the north, because they allow the panels to be laid out such that negative effects are minimized. Therefore, flat and north-oriented terrain received a higher grade (5) than steeper and south-oriented terrain (1) in this analysis.

To determine the vegetation density in the study area, a layer was created from the Normalized Difference Vegetation Index (NDVI) using satellite images from Landsat 8 OLI (U.S. Geological Survey, 2016). NDVI values range from $(-1)$ to $(+1)$, so all values less than or equal to 0 refers to no vegetation, while value close to +1 (0.8 and 0.9) indicates the highest density of green leaves (Weier \& Herring, 2000). A higher value for NDVI means a lower potential for PV and a lower NDVI value means a greater potential for PV.

\subsection{Geoprocessing}

First, a map of direct solar radiation was prepared, based on the data from NSRDB (Figure 6).

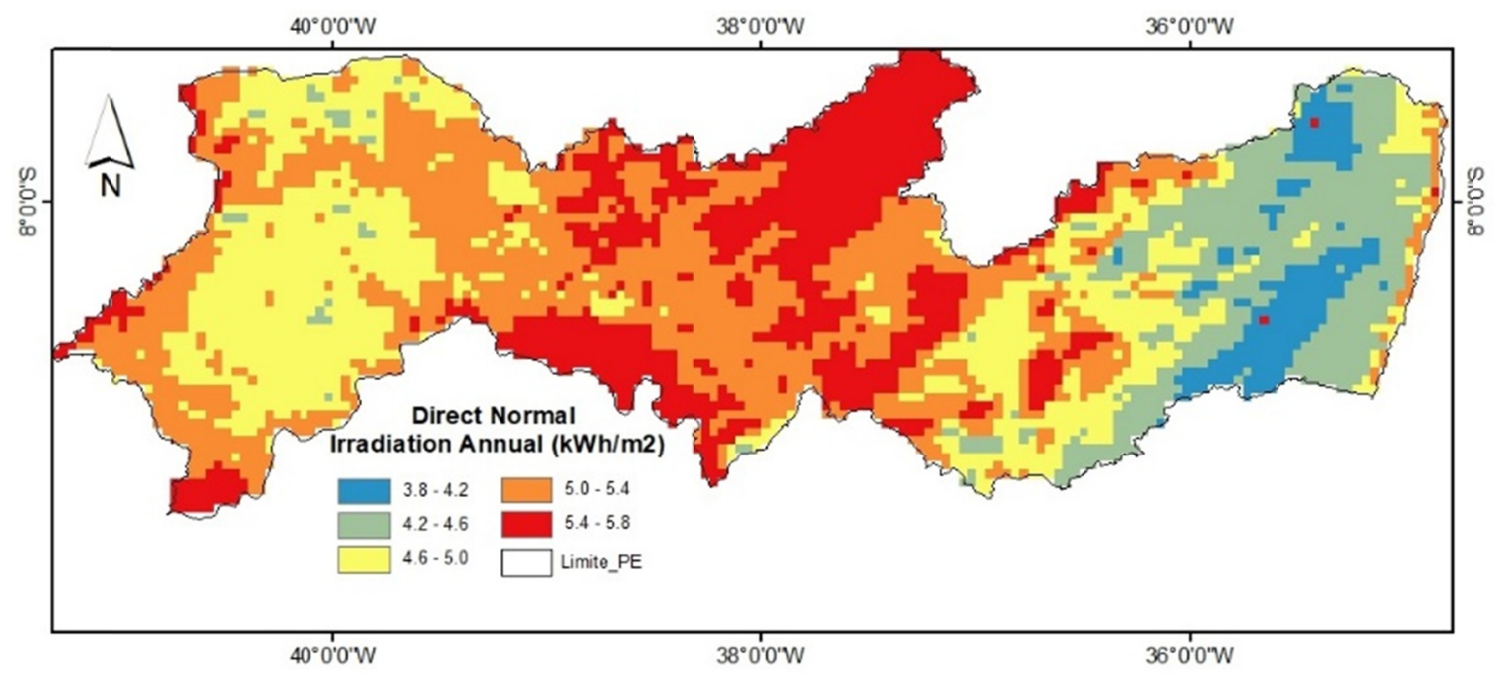

Figure 6. Map of direct solar radiation

From the input data, maps were prepared for the other selected criteria: slope (Figure 7), orientation (Figure 8), temperature (Figure 9), soil agricultural potential (Figure 10), and NDVI (Figure 11). The land use and 
occupation maps from IBGE allowed for the selection of areas classified as having a vegetation cover compatible with the installation of solar plants. Areas with a vegetation coverage below $30 \%$ were selected as having the greatest potential for PV.

Power lines, main roads, urban areas, and condition layers have been converted from vector to raster. The proximity of power lines, roads, and urban areas were calculated using the Euclidean Distance tool available in the Spatial Analyst extension of ArcGIS, making it possible to calculate distances for each raster cell based on a defined maximum or range. These maps were reclassified using equal intervals, prioritizing the areas closest to the infrastructure (Merrouni et al., 2018) (Figures 12, 13 and 14).

The next step was to cross the layer resulting from the previous operation with the layer containing urban planning information, where previously only areas classified as unusable common land were selected. In this way, all areas that could not be included for environmental or legal reasons were obtained, that is, restricted areas.

Unprotected and hazard-free areas, green infrastructure and hazard layers were overlaid and the hazard areas were eliminated from the total study area using map algebra.

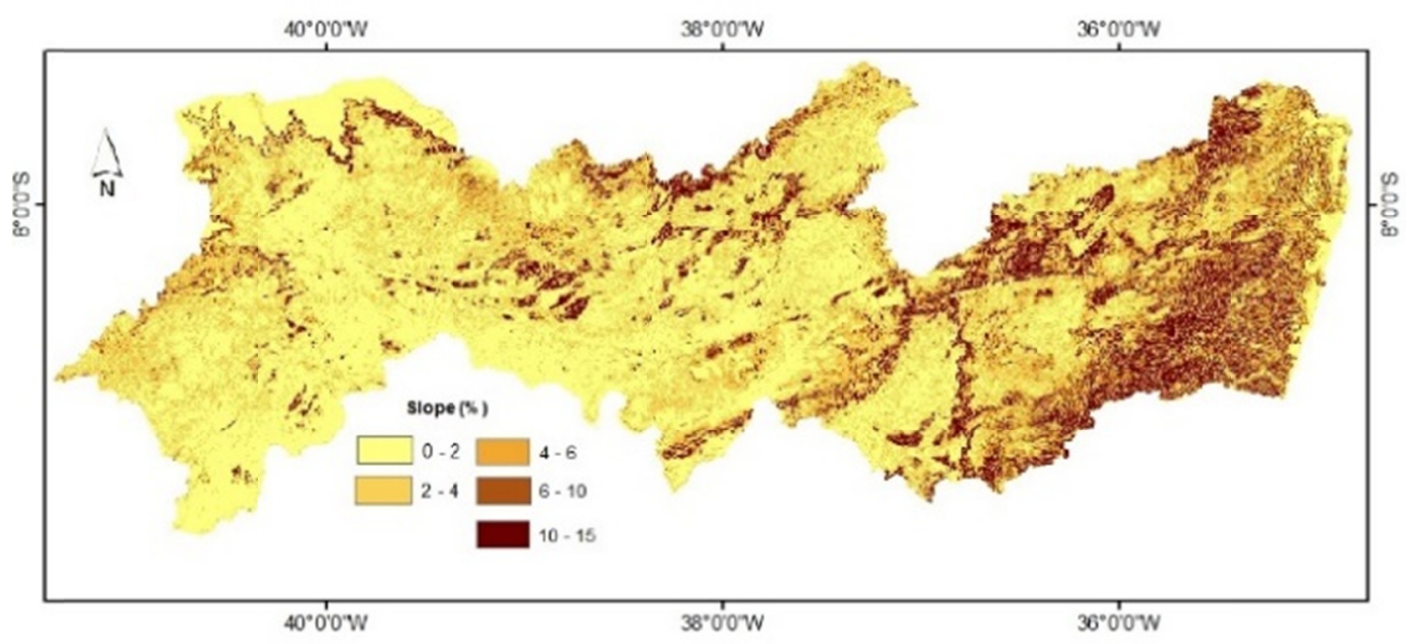

Figure 7. Slope map

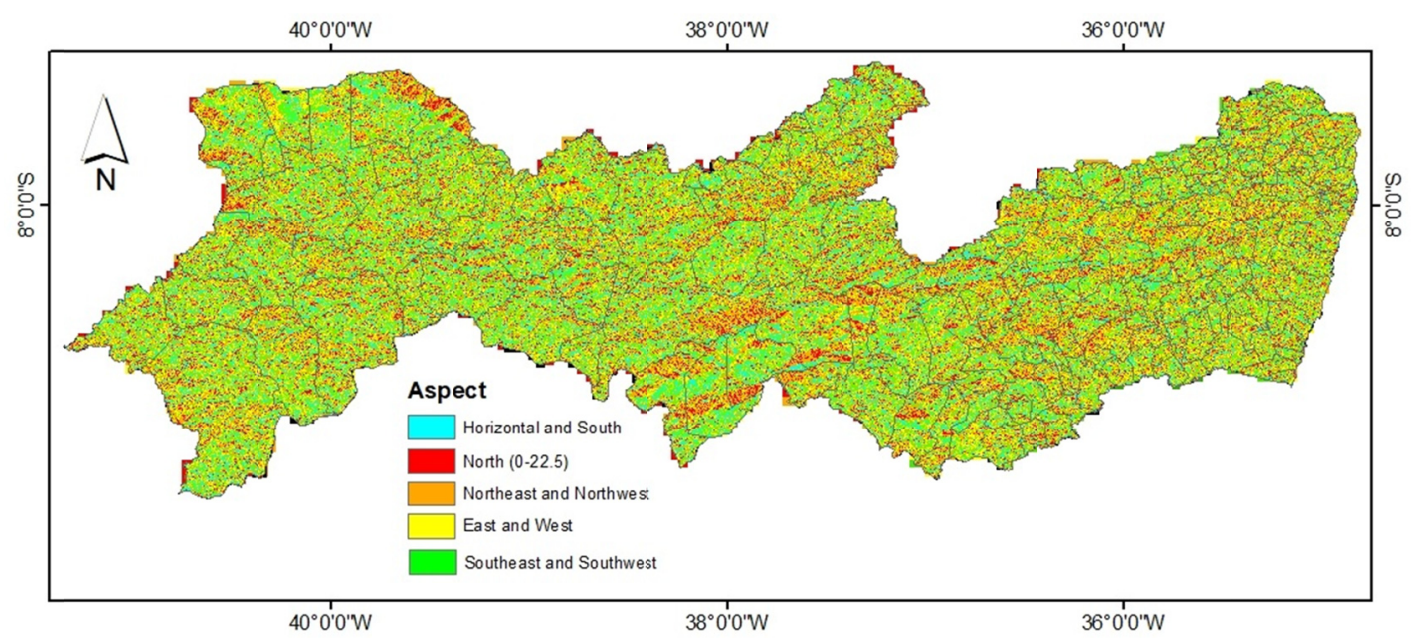

Figure 8. Aspect map 


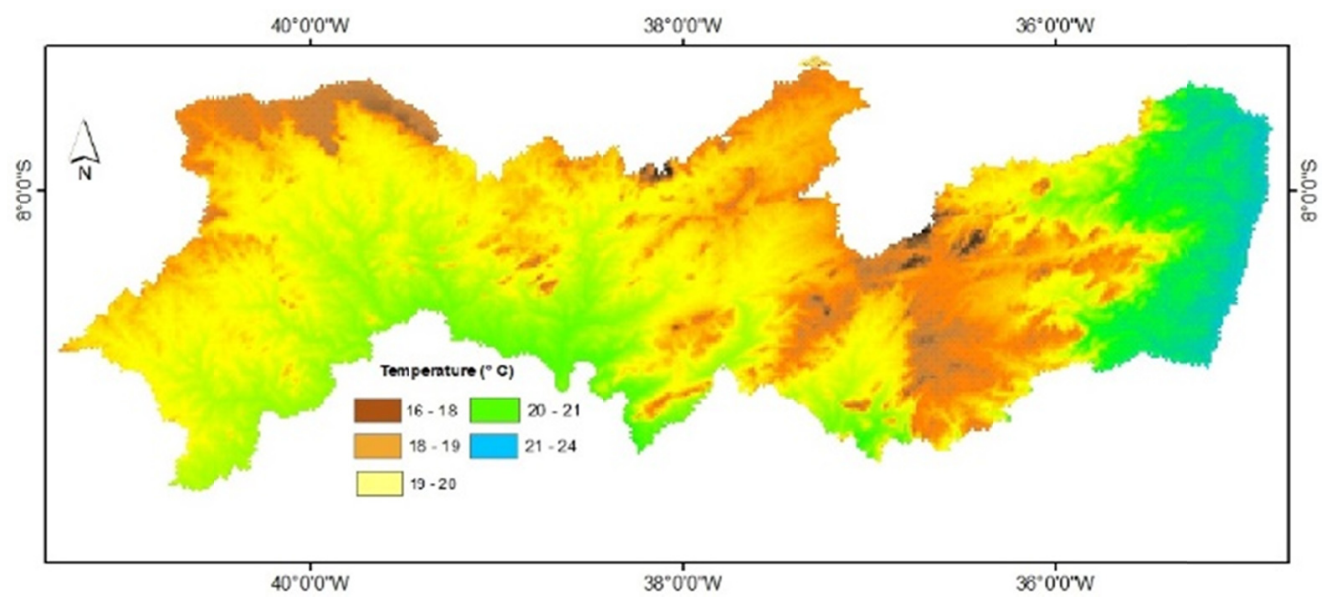

Figure 9. Map of average annual temperature

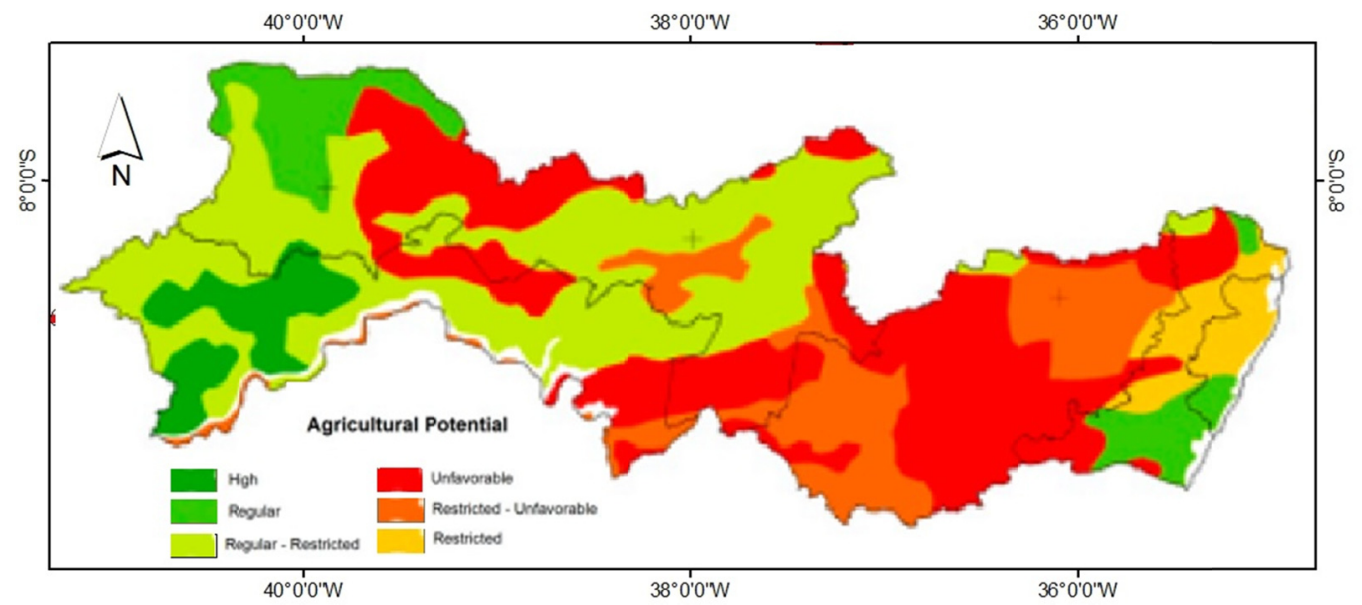

Figure 10. Soil potential for agriculture

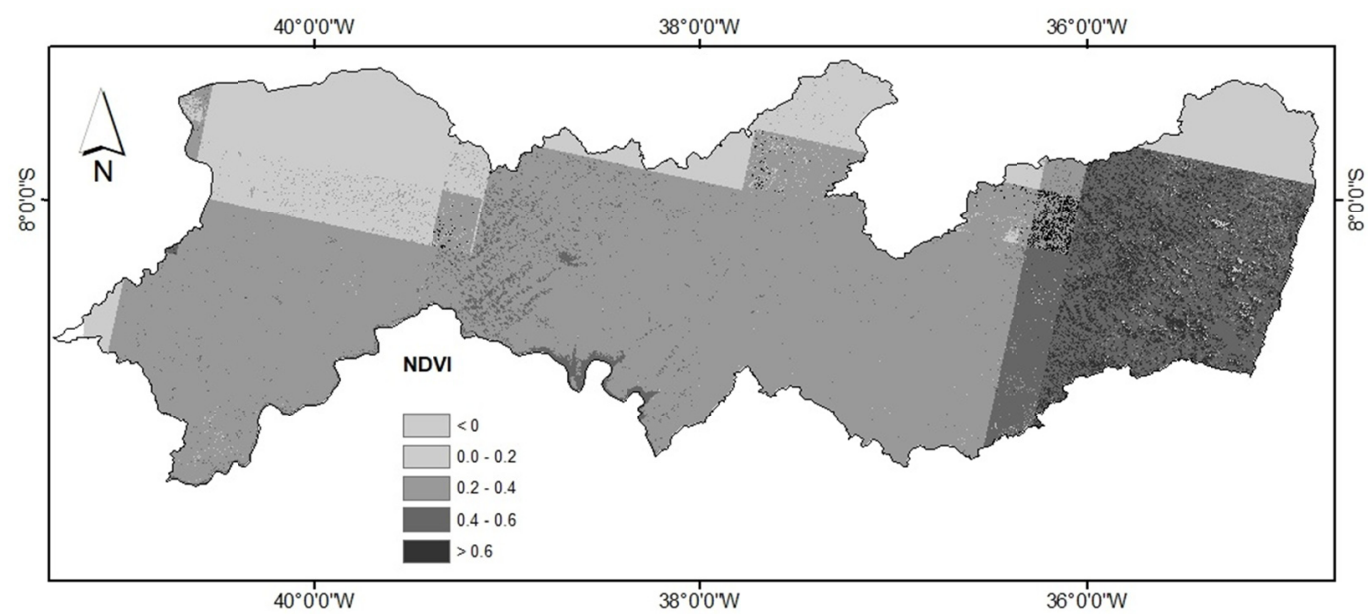

Figure 11. NDVI Map 


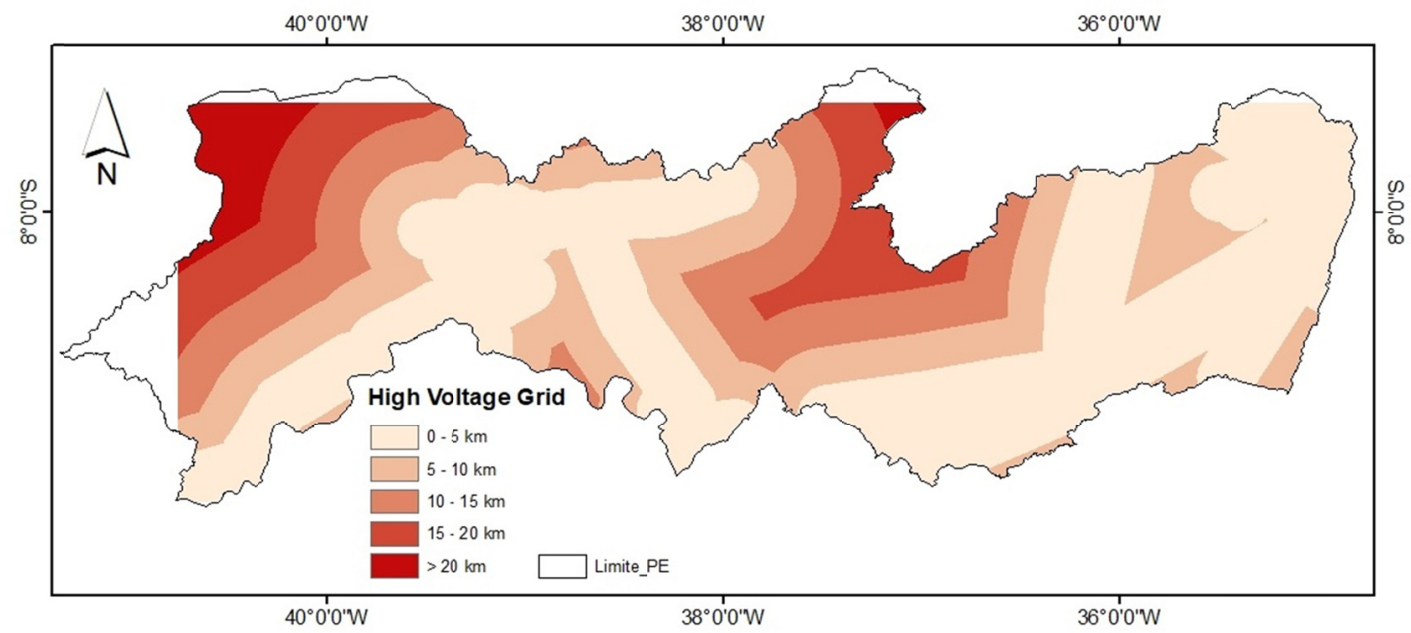

Figure 12. Distance from energy lines

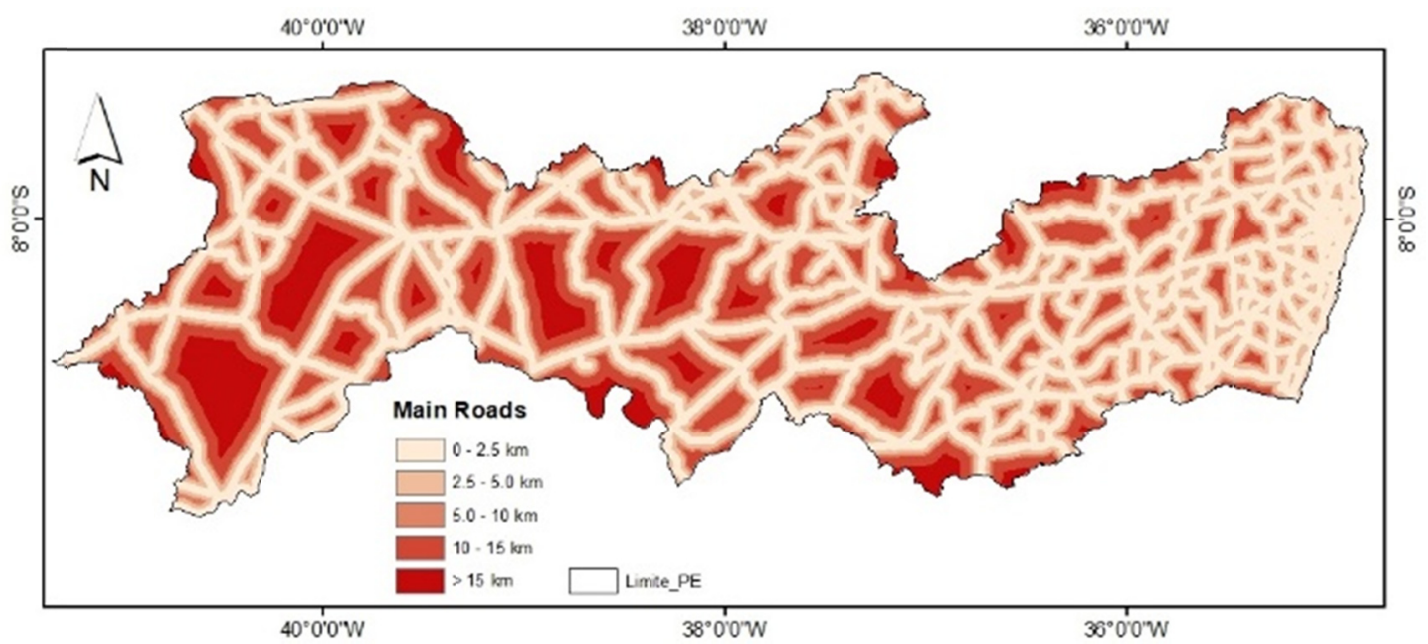

Figure 13. Distance from principal roads

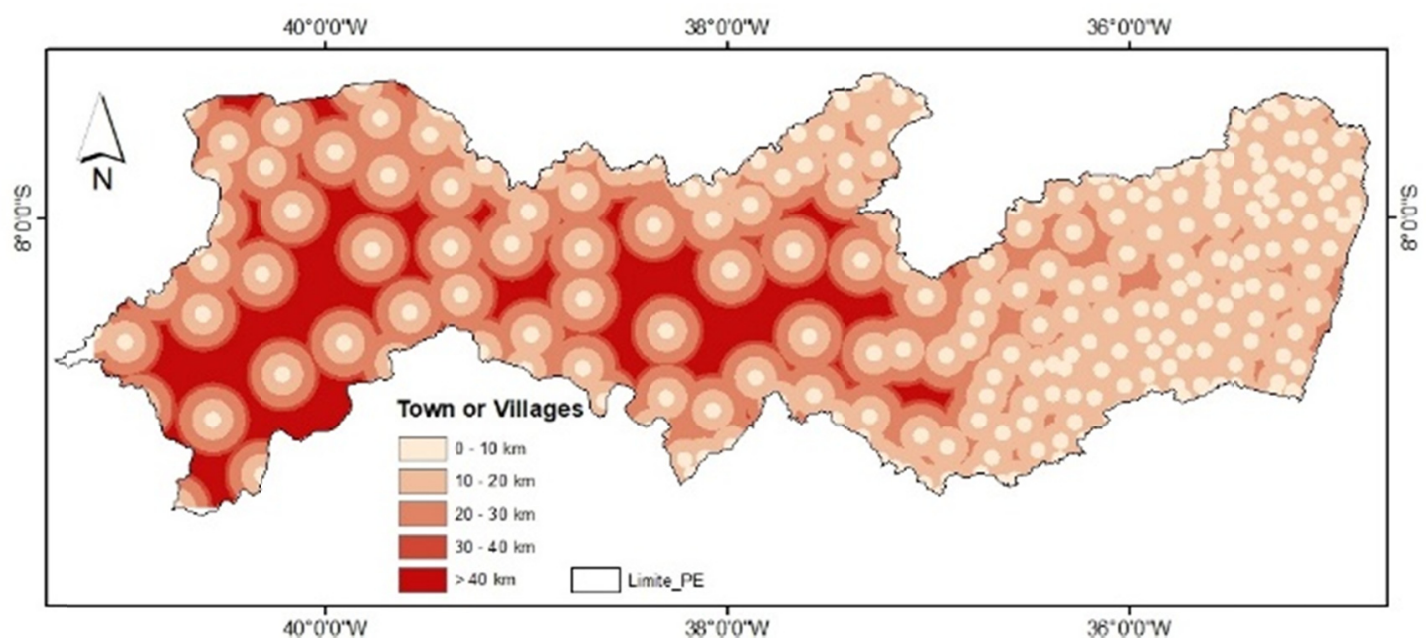

Figure 14. Distance from urban areas 


\subsection{Multi-criteria Analyses - Fuzzy AHP-TOPSIS}

The results of the previous step gave rise to a list of criteria and sub-criteria to be hierarchized in order to apply the model. The five-point Likert scale was used to classify the sub-criteria.

\subsubsection{Fuzzy-AHP}

The order of importance of the criteria based on expert assessment is shown in Table 6 .

Table 6. Order of importance of the criteria according to each specialist

\begin{tabular}{ll}
\hline Specialist & Order of importance of the criteria \\
\hline 1 & $\mathrm{C} 1>\mathrm{T} 2=\mathrm{T} 1=\mathrm{C} 2>\mathrm{T} 3=\mathrm{L} 1=\mathrm{V} 1=\mathrm{L} 3>\mathrm{L} 2>\mathrm{E} 1$ \\
2 & $\mathrm{C} 1>\mathrm{T} 1=\mathrm{E} 1=\mathrm{T} 3>\mathrm{T} 2=\mathrm{C} 2>\mathrm{L} 2=\mathrm{L} 1>\mathrm{L} 3>\mathrm{V} 1$ \\
3 & $\mathrm{C} 1=\mathrm{E} 1>\mathrm{L} 1=\mathrm{T} 1=\mathrm{T} 3>\mathrm{L} 2=\mathrm{C} 2=\mathrm{T} 2=\mathrm{L} 3>\mathrm{V} 1$ \\
\hline
\end{tabular}

Once the decision rule for each scenario was established, the pairwise comparison be-tween the criteria could be performed. The consistency ratio (CR) for each specialist, the highest eigenvalues ( $\lambda$ max) found, and the consistency indices of the judgments (CI) are shown in Table 7.

Table 7. Consistency ratios of criteria matrices

\begin{tabular}{|c|c|c|c|c|c|c|c|c|c|c|c|c|}
\hline \multirow[t]{2}{*}{ Dimension } & \multicolumn{4}{|l|}{ E1 } & \multicolumn{4}{|l|}{$\mathrm{E} 2$} & \multicolumn{4}{|l|}{ E3 } \\
\hline & & $\mathrm{CR}$ & $\lambda \max$ & $\mathrm{CI}$ & & $\mathrm{CR}$ & $\lambda \max$ & $\mathrm{CI}$ & & $\mathrm{CR}$ & $\lambda \max$ & $\mathrm{CI}$ \\
\hline Topographic & 0.022 & 0.058 & 5.25 & 0.06 & 0.029 & 0.058 & 5.43 & 0.05 & 0.029 & 0.056 & 5.28 & 0.06 \\
\hline Environmental & 0.012 & & & & 0.015 & & & & 0.012 & & & \\
\hline Economic & 0.001 & & & & 0.000 & & & & 0.000 & & & \\
\hline Location & 0.009 & & & & 0.008 & & & & 0.008 & & & \\
\hline Climatic & 0.047 & & & & 0.048 & & & & 0.051 & & & \\
\hline
\end{tabular}

With all of the criteria organized hierarchically, the process of obtaining the vectors from the priority and consistency assessment was carried out for the criteria and sub-criteria using the fuzzy AHP method. As the CR value is less than 0.10 for all specialists, the estimated values of the sub-criteria are also confirmed to be consistent. Final weights are shown in Tables 8 and 9, respectively.

Table 8. Criteria weighting using the Fuzzy AHP method

\begin{tabular}{|c|c|c|c|c|c|c|c|c|c|}
\hline \multirow[t]{3}{*}{ Dimension } & \multicolumn{9}{|c|}{ Criterion weighting } \\
\hline & \multicolumn{3}{|c|}{ E1 } & \multicolumn{3}{|l|}{ E2 } & \multicolumn{3}{|l|}{ E3 } \\
\hline & a1 & a2 & a3 & a1 & a2 & a3 & a1 & a2 & a3 \\
\hline Topographic & 0.1623 & 0.3319 & 0.818 & 0.1623 & 0.3319 & 0.818 & 0.1623 & 0.3319 & 0.818 \\
\hline Environmental & 0.0183 & 0.0496 & 0.1041 & 0.0183 & 0.0496 & 0.1041 & 0.0183 & 0.0496 & 0.1041 \\
\hline Economic & 0.2133 & 0.5383 & 1.1959 & 0.2133 & 0.5383 & 1.1959 & 0.2133 & 0.5383 & 1.1959 \\
\hline Location & 0.0181 & 0.0465 & 0.1142 & 0.0181 & 0.0465 & 0.1142 & 0.0181 & 0.0465 & 0.1142 \\
\hline Climatic & 0.0168 & 0.0336 & 0.0998 & 0.0168 & 0.0336 & 0.0998 & 0.0168 & 0.0336 & 0.0998 \\
\hline
\end{tabular}

Table 9. Sub-criteria weighting using the Fuzzy AHP method

\begin{tabular}{|c|c|c|c|c|c|c|c|c|c|}
\hline \multirow[t]{3}{*}{ Subcriteria } & \multicolumn{9}{|c|}{ Subcriteria weighting } \\
\hline & \multicolumn{3}{|l|}{ E1 } & \multicolumn{3}{|l|}{$\mathrm{E} 2$} & \multicolumn{3}{|l|}{ E3 } \\
\hline & $\mathrm{a} 1$ & $\mathrm{a} 2$ & a3 & a1 & $\mathrm{a} 2$ & a3 & a1 & $\mathrm{a} 2$ & a3 \\
\hline $\mathrm{T} 1$ & 0.072 & 0.401 & 1.649 & 0.059 & 0.602 & 1.322 & 0.059 & 0.401 & 1.649 \\
\hline $\mathrm{T} 2$ & 0.046 & 0.112 & 0.384 & 0.042 & 0.108 & 0.367 & 0.042 & 0.112 & 0.384 \\
\hline E1 & 0.068 & 0.114 & 0.497 & 0.056 & 0.114 & 0.438 & 0.056 & 0.114 & 0.497 \\
\hline E2 & 0.043 & 0.165 & 0.451 & 0.046 & 0.099 & 0.412 & 0.046 & 0.165 & 0.451 \\
\hline V1 & 0.012 & 0.033 & 0.190 & 0.026 & 0.038 & 0.194 & 0.026 & 0.033 & 0.190 \\
\hline L1 & 0.067 & 0.178 & 0.554 & 0.067 & 0.168 & 0.494 & 0.067 & 0.178 & 0.554 \\
\hline L2 & 0.040 & 0.201 & 0.793 & 0.048 & 0.198 & 0.796 & 0.048 & 0.201 & 0.793 \\
\hline L3 & 0.054 & 0.165 & 0.568 & 0.062 & 0.139 & 0.544 & 0.062 & 0.165 & 0.568 \\
\hline $\mathrm{C} 1$ & 0.124 & 0.475 & 1.354 & 0.114 & 0.423 & 1.424 & 0.114 & 0.475 & 1.354 \\
\hline $\mathrm{C} 2$ & 0.013 & 0.042 & 0.218 & 0.017 & 0.032 & 0.118 & 0.017 & 0.042 & 0.218 \\
\hline
\end{tabular}


In order to unify the weightings for the obtained criteria, a homogeneous aggregation was performed, that is, all specialists were considered to be equally important in the decision. The arithmetic mean was used as an aggregation measure. The criteria weightings obtained from the homogeneous aggregation are shown in Table 10 .

Table 10. The criteria weightings obtained from the homogeneous aggregation

\begin{tabular}{lllll}
\hline Dimension & Subcriterion & $\mathrm{a} 1$ & $\mathrm{a} 2$ & $\mathrm{a} 3$ \\
\hline Topographic & $\mathrm{T} 1$ & 0.072 & 0.401 & 1.649 \\
& $\mathrm{~T} 2$ & 0.046 & 0.112 & 0.384 \\
Environmental & E1 & 0.068 & 0.114 & 0.497 \\
& $\mathrm{E} 2$ & 0.043 & 0.165 & 0.451 \\
Economic & $\mathrm{V} 1$ & 0.012 & 0.033 & 0.190 \\
Location & L1 & 0.067 & 0.178 & 0.554 \\
& $\mathrm{~L} 2$ & 0.040 & 0.201 & 0.793 \\
& $\mathrm{~L} 3$ & 0.054 & 0.165 & 0.568 \\
Climatic & $\mathrm{C} 1$ & 0.124 & 0.475 & 1.354 \\
& $\mathrm{C} 2$ & 0.013 & 0.042 & 0.218 \\
\hline
\end{tabular}

\subsubsection{Fuzzy-TOPSIS}

Once the weightings for the criteria that influence PVP location were defined, the alternatives were evaluated using the fuzzy TOPSIS method. The evaluation matrix was normalized, to arrive at the normalized and weighted matrix $\tilde{V}$, using Equation 4 and Equation 5. With the standardized and calibrated fuzzy values, the distances between these data and the ideal positive and negative fuzzy solutions were calculated, which are the maximum and minimum values for each criterion and sub-criterion. Then, the distance matrices $\mathrm{A}+$ and $\mathrm{A}-$ were generated using Equations 6 and 7, respectively, and the $\mathrm{CCi}$ of the criteria and sub-criteria was calculated. The results are presented in Table 11 and Table 12. The best alternatives are shown in decreasing order according to $\mathrm{CCi}$, The results defined with this coefficient will be counted in ArcGis 10.3.

Table 11. The criteria distances to PIS (D+), to NIS (D-) and the CCi approximation coefficients

\begin{tabular}{lllll}
\hline Dimension & $\mathrm{di}+$ & $\mathrm{di}-$ & $\mathrm{CCi}$ & $\mathrm{Rank}$ \\
\hline Location & 0.089 & 0.072 & 0.446 & 4 \\
Economic & 0.110 & 0.065 & 0.370 & 5 \\
Climatic & 0.065 & 0.110 & 0.630 & 1 \\
Topographic & 0.087 & 0.085 & 0.494 & 2 \\
Environmental & 0.094 & 0.085 & 0.476 & 3 \\
\hline
\end{tabular}

Table 12. The sub-criteria distances to PIS (D+), to NIS (D-) and the CCi approximation coefficients

\begin{tabular}{lllll}
\hline Subcriterion & $\mathrm{di}+$ & $\mathrm{di}-$ & $\mathrm{CCi}$ & Rank \\
\hline $\mathrm{T} 1$ & 5.346 & 6.062 & 0.531 & 3 \\
$\mathrm{~T} 2$ & 5.379 & 6.003 & 0.529 & 4 \\
$\mathrm{E} 1$ & 5.448 & 5.971 & 0.527 & 5 \\
$\mathrm{E} 2$ & 5.870 & 5.447 & 0.522 & 6 \\
$\mathrm{~V} 1$ & 8.324 & 2.021 & 0.112 & 10 \\
$\mathrm{~L} 1$ & 6.919 & 4.089 & 0.371 & 7 \\
$\mathrm{~L} 2$ & 7.102 & 4.003 & 0.399 & 8 \\
$\mathrm{~L} 3$ & 7.223 & 3.978 & 0.442 & 9 \\
$\mathrm{C} 1$ & 4.083 & 8.091 & 0.664 & 1 \\
$\mathrm{C} 2$ & 4.683 & 7.842 & 0.607 & 2 \\
\hline
\end{tabular}

\subsubsection{Results from the Fuzzy AHP-TOPSIS Method}

The pairwise comparison matrix was calculated using the fuzzy-AHP method. The hierarchical decision data were constructed based on the literature and following discussions with specialists in the area regarding the specificity of the region. The results of the pairwise comparisons in this study are acceptable and the values are very consistent, with the consistency ratio (CR) equal to 0.058 . 
From an analysis of the criteria and sub-criteria weightings using the fuzzy TOPSIS method, it can be seen that the climatic criterion is the most dominant, with a weight of $51 \%$. This is because the production of electrical energy is directly linked to the amount of solar radiation available. Therefore, to be competitive in the domestic market, suitable locations for photovoltaic plants must be located in well irradiated locations.

Topography is the second most important criterion in the fuzzy AHP-TOPSIS analysis. This is reasonable because the presence of slopes significantly increases investment costs during the construction of photovoltaic plants. In this study, slopes of less than $5 \%$ were chosen as ideal, in order to ensure that locations with high capacity for PV installations will be relatively flat, consequently requiring lower investment costs for earthworks. The weight of the topography criterion is $29 \%$.

The third most important criterion was land use. This can be justified because the most favorable areas for PV are those with unfavorable agricultural potential. Another important factor in this criterion is the presence or absence of trees, which can cast shade on photovoltaic modules and reduce energy efficiency. The weight for this criterion is $12 \%$.

PV location is the fourth criterion, with a weighting of $8 \%$. The economic criterion was not representative, and therefore given a weight of $0 \%$.

\subsection{Identification of Sites Appropriate for PV}

The input data sets used for the GIS model were subject to various raster processing and spatial analysis operations in order to implement the integrated multi-criteria analysis in ArcGIS 10.3 Software. These operations resulted in nine input layers to be used for spatial analysis: slope, orientation, direct solar radiation, temperature, distance to transmission lines, distance to main roads, distance to water resources, land use, and NDVI.

The Weighted Sum tool available in the ArcGIS 10.3 Spatial Analyst extension made it possible to combine these nine input layers and assign them the weights defined by the fuzzy AHP-TOPSIS analysis, thereby obtaining the most suitable locations for photovoltaic solar plants. This model can easily be modified to use different criteria or weights. The result was a map of areas that met all of the conditions and criteria established (Figure 15).

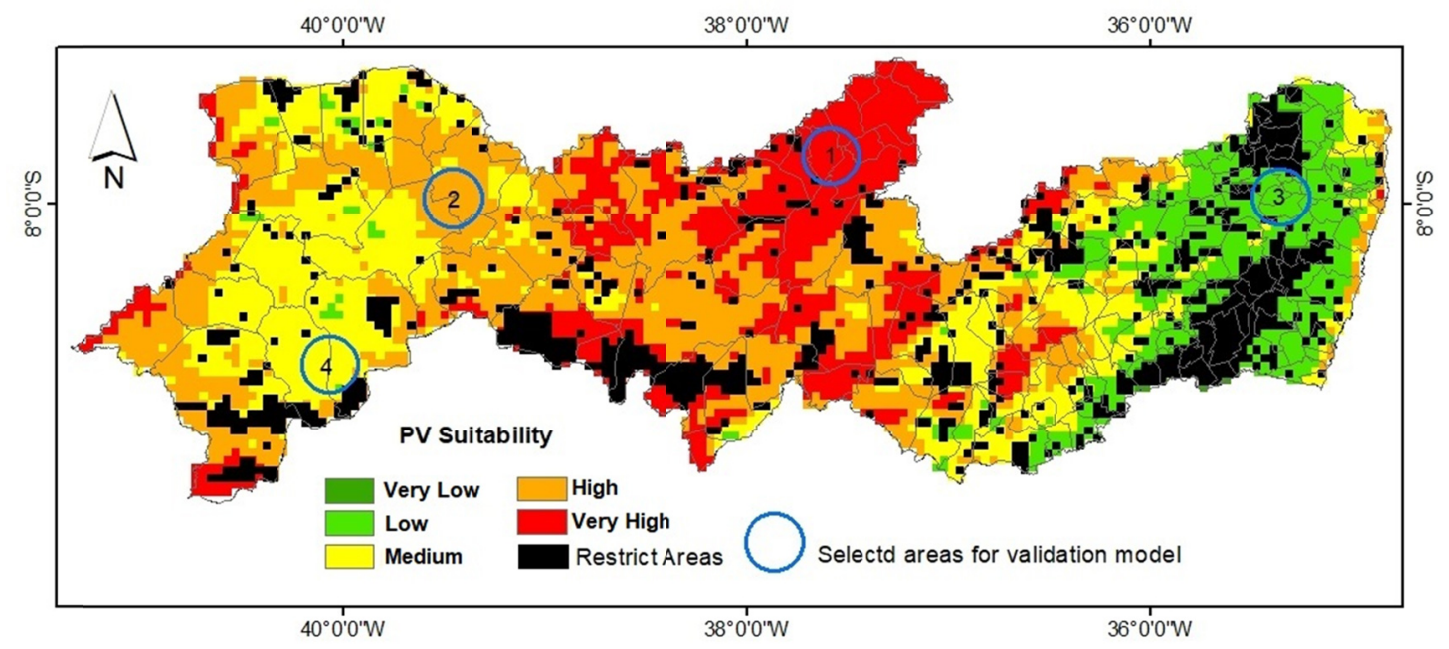

Figure 15. Places appropriate for solar photovoltaic plants

The resulting geographical and technical potentials were classified into five categories: Very High, High, Medium, Low, and Very low. The results show that the choice of restrictive criteria, variables, and their weightings play a critical role in estimating the potential for solar energy plants, especially with regard to the assessment of site fitness.

These potential sites must also be evaluated according to the requirements of solar technology. Most of the areas identified to have the greatest potential for photovoltaic plants are located in the Sertão mesoregion (Very High and High) and in the São Francisco mesoregion (Medium). The areas with the lowest suitability are in the Agreste mesoregion (Medium and Low), Mata Pernambucana (Low), and Recife Metropolitan Area (Very Low). Table 13 shows the areas of each suitability class and their percentages in relation to the PV-favorable areas and to the total area of the state of Pernambuco. 
Table 13. Areas of each suitability class and their percentages in relation to the PV-favorable areas and to the total area of the state of Pernambuco

\begin{tabular}{lllll}
\hline PV Suitability & Map color & Area $\left(\mathrm{km}^{2}\right)$ & Area $(\%)$ & Area of the state $(\%)$ \\
\hline Very High & Red & $12,379.69$ & 21.96 & 12.61 \\
High & Orange & $22,331.51$ & 39.61 & 22.75 \\
Medium & Yellow & $18,141.42$ & 32.18 & 18.48 \\
Low & Light Green & 114.75 & 0.21 & 0.12 \\
Very Low & Dark Green & 301.89 & 0.53 & 0.31 \\
\hline
\end{tabular}

Four areas were selected for evaluation. Area 1 is located in the Sertão (Figure 15). Assessing the influence of the weighting of the thematic layers in the definition of the suitability map, it was noticed that, the solar radiation layer presented values above $5.3 \mathrm{kWh} / \mathrm{m} 2 \cdot$ day throughout its territory. Solar radiation had a weighting of $42 \%$. The land slope layer shows that the slope of the municipality's land is less than $5 \%$ in the central and northern portions. The slope layer was the second in order of importance, with a weighting of $26 \%$. Regarding land use, most of Salgueiro's territory is composed of land that is unfavorable for agriculture, which is the class that most favors the installation of PVPs. This parameter has a weighted value of $18 \%$, third in order of importance. Finally, in relation to the infrastructural aspects for interconnection to the grid, the area is close to $69 \mathrm{kV}$ transmission lines and the BR-232 highway.

Areas 2 and 4 are located in the Sertão and São Francisco mesoregions (Figure 15). These areas also had solar radiation values above $5.3 \mathrm{kWh} / \mathrm{m} 2 \cdot$ day (annual average) throughout their territory. This terrain also has slopes of less than $5 \%$ and was close to $69 \mathrm{kV}$ transmission lines and state highways. The big difference with the first area is due to the land use, with most of the territory being composed of land having favorable agricultural potential, disadvantaging the installation of PVPs. Mainly in the São Francisco mesoregion, there are several farms with mango and grape plantations, responsible for the region's economic development and for supplying the international market.

The lowest suitability class, area 3 (Figure 15), was found in the Recife Metropolitan Area, where the solar radiation is between $3.5 \mathrm{kWh} / \mathrm{m} 2 \cdot$ day and $4.8 \mathrm{kWh} / \mathrm{m} 2 \cdot$ day and the slope of the terrain is greater than $5 \%$. These regions are closer to urban areas and electrical and road infrastructure. They also are for the installation of photovoltaic plant projects, considering the distances to urban areas, but when it comes to land use, there are restrictions due to the presence of remnants of the Atlantic Rain Forest.

To better refine the research methodology, a minimum area limit, based on the generation capacity of the plant, can be applied to systems connected to the grid on a large scale. The land occupation factor can have separate values for rural areas (or built areas) and other available surfaces. However, when working on a regional scale, it is difficult to determine the exact value of the land occupation factor for built-up areas. In addition, the population density may be different for systems connected to the network on a large scale. In other words, all inhabited pixels (population density $>0$ inhabitants $/ \mathrm{km} 2$ ) can be classified as the most suitable (score 5), and non-inhabited pixels can be classified as the least suitable (score 1).

A sensitivity analysis can be carried out with regard to the technical characteristics of the chosen technologies. In this study, it is proposed that large-scale systems connected to the network be located away from cities (that is, preference should be given to greater distances from urban areas). The objective is to avoid restrictions on urban development and to choose places with lower land value. However, a maximum distance limit can be applied in order to reduce losses during electricity transmission.

The uncertainty discussed in the methodological choices demonstrates a need for more research and dialogue (including academia, legislators, and other stakeholders actively involved in the deployment of photovoltaic plants) with respect to approaches that estimate potentials for large-scale solar energy generation (i.e., at a national or regional level).

Estimates should not be limited to only geographic and technical potentials, but should include an economic evaluation, as this information is essential for investment planning. For this reason, a more detailed analysis of this criterion is suggested to analyze any possible flaws in the methodology.

\section{Discussion}

For the sustainable development of a region, it is extremely beneficial to identify areas suitable for the deployment of solar photovoltaic plants to optimize the planning of transmission lines, strengthen the solar energy market, and develop master plans for the production of solar energy, among others. The evaluation of 
different alternative locations in planning is a preliminary and decisive step in creating maps with suitable and economically-viable locations for the use of specific technologies.

In this study, spatial analysis began from the definition of the criteria with which the areas for solar photovoltaic plant installation would be selected. The choice of criteria was based on the available literature on this subject: essential criteria imposed by government legislation and expert opinions on the performance of solar plants. The chosen criteria were then classified into three categories: technical, environmental, and social. Site selection involves screening a large geographic area to select a limited number of alternatives. The locations identified by the screening must be evaluated later, which will lead to finding the most suitable location among all available alternatives.

The principal contribution of this article was its methodology that combines GIS with a multi-criteria decision analysis method (fuzzy AHP-TOPSIS). The main advantage offered by this integrated approach is to be able to use a GIS to collect and organize the information that will be provided to the AHP. The application of the fuzzy AHP-TOPSIS for the locations of PVPs proved to be an accurate and adequate tool for hierarchizing the criteria and sub-criteria. The results showed that Pernambuco can be considered a highly suitable state for PVP. The areas having very high potential represent $12.61 \%$ of the entire state. The percentage of high and medium potential is $22.75 \%$ and $18.48 \%$ whereas inadequate sites with low and very low potential represent $0.12 \%$ and $0.31 \%$, respectively.

GIS-based methods can be applied differently according to the scale of the study area, as well as the type of solar energy conversion technology. The results show that solar radiation maps can be used as banks of spatial data useful in spatial and temporal analysis of solar resources. In particular, site assessment using GIS is useful to support decision-making on a regional scale, and it is necessary to consider the economic, environ-mental, technical, social and risk factors, in addition to solar radiation. These factors can be used to exclude inappropriate regions using map algebra. The functions of GISs can extend beyond being a data and visualization inventory to sophisticated modeling, evaluation, and interdisciplinary studies of solar energy.

\section{Acknowledgments}

The authors would like to thank the University of Pernambuco, its Polytechnic School of Engineering, and its Civil Engineering Master's Program for their financial support and infrastructure for the development, translation, and publication of the article. The authors would also like to thank the meticulous and dedicated translation work by Simeon Kohlman Rabbani.

\section{References}

ABSOLAR. (2019). Infográfico.

ANEEL-Agência Nacional de Energia Elétrica. (2020). Resolução Normativa 486 de 17 de abril de 2012. revision 2020.

Arán-Carrión, J., Espín-Estrella, A., Aznar-Dols, F., Zamorano-Toro, M., Rodríguez, M., \& Ramos-Ridao, A. (2008). Environmental decision-support systems for evaluating the carrying capacity of land areas: Optimal site selection for grid connected photovoltaic power plants. Renew Sustain Energy Rev., 12, 2358-2380. https://doi.org/10.1016/j.rser.2007.06.011

Arce, M. E. (2015). The use of grey-based methods in multi-criteria decision analysis for the evaluation of sustainable energy systems: A review. Renewable and Sustainable Energy Re-views, 47, 924-932. https://doi.org/10.1016/j.rser.2015.03.010

Aydin, Y. N., Kentel, E., \& Duzgun, H. S. (2013). GIS-based site selection methodology for hybrid renewable energy systems: A case study from western Turkey. Energy Convers. Manag., 70, 90-106. https://doi.org/10.1016/j.enconman.2013.02.004

Azevêdo, V. W. B., Candeias, A. L. B., \& Tiba, C. (2017). Location Study of Solar Thermal Power Plant in the State of Pernambuco Using Geoprocessing Technologies and Multiple-Criteria Analysis. Energies, 10, 1042. https://doi.org/10.3390/en10071042

Charabi, Y., \& Gastli, A. (2011). PV site suitability analysis using GIS-based spatial fuzzy multi-criteria evaluation. Renew Energy, 36, 2554-2561. https://doi.org/10.1016/j.renene.2010.10.037

da Ponte, G. P., Calili, R. F., \& Souza, R. C. (2021). Energy generation in Brazilian isolated systems: Challenges and proposals for increasing the share of renewables based on a multi-criteria analysis. Energy for Sustainable Development, 61, 74-88. https://doi.org/10.1016/j.esd.2020.12.007 
Instituto Brasileiro de Geografia e Estatística (IBGE). (2019). Diagnóstico Cartográfico dos Munícipios do Brasil. Brasília.

Janke, J. R. (2010). Multi-criteria GIS modeling of wind and solar farms in Colorado. Renew Energy, 35, 2228-2234. https://doi.org/10.1016/j.renene.2010.03.014

Kaya, T., \& Kahraman, C. (2010). Multi-criteria renewable energy planning using an integrated fuzzy VIKOR \& AHP methodology: The case of Istanbul. Energy, 35, 2517-2527. https://doi.org/10.1016/j.energy.2010.02.051

Lee, M., Koo, C., Hong, T., \& Park, H. S. (2014). Framework for the Mapping of the Monthly Average Daily Solar Radiation Using an Advanced Case-Based Reasoning and a Geostatistical Technique. Environ. Sci. Technol., 48, 4604-4612. https://doi.org/10.1021/es405293u

Macedo, M. R. O. B. C., Maia, M. L. A., Kohlman, R. E. R., \& Lima, N. O. C. C. (2020). Remote Sensing Applied to the Extraction of road geometric features based on OPF classifiers, Northeastern Brazil. Journal of Geographic Information System, 12, 15-44. https://doi.org/10.4236/jgis.2020.121002

Macedo, M. R. O. B. C., Times, V. C., Cavalcanti, G. D. C., \& Kohlman, R. E. R. (2015) An Architecture to Classify Desertification Areas using Hyperspectral Images and the Optimum Path Forest Algorithm. Electronic Journal of Geotechnical Engineering, 20, 1881-1895.

Maleki, S. A. M., Hizam, H., \& Gomes, C. (2017). Estimation of Hourly, Daily and Monthly Global Solar Radiation on Inclined Surfaces: Models Re-Visited. Energies, 10, 1-28. https://doi.org/10.3390/en10010134

Merrouni, A. A., Elalaoui, F. E., Mezrhab, A., \& Ghennioui, A. (2018). Large scale PV sites selection by combining GIS and Analytical Hierarchy Process. Case study: Eastern Morocco. Renew. Energy, 119, 863-873. https://doi.org/10.1016/j.renene.2017.10.044

Merrouni, A. A., Mezrhab, A., \& Mezrhab, A. (2016). PV sites suitability analysis in the Eastern region of Morocco. Sustain. Energy Technol. Assess., 18, 6-15. https://doi.org/10.1016/j.seta.2016.09.006

Oliveira, F. T. V., \& Gómez-Malagón, L. A. (2018). Otimização do ângulo de inclinação e orientação de painéis solares para a cidade de petrolina. VII Congresso Brasileiro de Energia Solar - Gramado, 17 a 20 de abril de 2018.

Phuangpornpitak, N., \& Tia, S. (2016). Opportunities and challenges of integrating renewable energy in smart grid system. Energy Procedia, 34, 282-290. https://doi.org/10.1016/j.egypro.2013.06.756

Pinto, J. T. M., Amaral, K. J., \& Janissek, P. R. (2016). Deployment of photovoltaics in Brazil: Scenarios, perspectives and policies for low-income housing. Solar Energy, 133, 73-84. https://doi.org/10.1016/j.solener.2016.03.048

Sánchez-Lozano, J. M., García-Cascales, M. S., \& Lamata, M. T. (2016). GIS-based onshore wind farm site selection using Fuzzy Multi-Criteria Decision Making methods. Evaluating the case of Southeastern Spain. Appl. Energy, 171, 86-102. https://doi.org/10.1016/j.apenergy.2016.03.030

Şengül, Ü. (2014). Fuzzy TOPSIS method for ranking renewable energy supply systems in Turkey. Renewable Energy, 75, 617-625. https://doi.org/10.1016/j.renene.2014.10.045

Sengupta, M., Xie, Y., Lopez, A., Habte, A., Maclaurin, G., \& Shelby, J. (2018). The National Solar Radiation Data Base (NSRDB). Renewable and Sustainable Energy Reviews, 89, 51-60. https://doi.org/10.1016/j.rser.2018.03.003

Skoplaki, E., \& Palyvos, J. A. (2008). Operating temperature of photovoltaic modules: A survey of pertinent correlations. Renewable Energy, 34, 23-29. https://doi.org/10.1016/j.renene.2008.04.009

Tahri, M., Hakdaoui, M., \& Maanan M. (2015). The evaluation of solar farm locations applying ge-ographic information system and multi-criteria decision-making methods: case study in Southern Morocco. Renew Sustain Energy Rev., 51, 1354-1362. https://doi.org/10.1016/j.rser.2015.07.054

Tiba, C., Reis, R. J. R., Costa, J. C. E., Azevêdo, V. W. B., Abreu, J. F., Alves, M. A. S., ... Porto, M. A. D. (2014). Siting Study of Solar Thermoelectric Plants in the State of Minas Gerais. JGIS, 6, 423-493. https://doi.org/10.4236/jgis.2014.65037

Trindade, J. E. D. O. (2016). Mensuração e avaliação da capacidade inovativa demicro, pe-quenas e médias empresas: aplicação de métodos multicritério fuzzy de apoio à decisão (p. 107). Rio de Janeiro, 2016. 
Dissertação (Mestrado). Programa de Pós-graduação em Metrologia. Pontifícia Universidade Católica do Rio de Janeiro.

Weier, J., \& Herring, D. (2000). Measuring vegetation (NDVI \& EVI): Normalized difference vegetation index (NDVI).

Wong, M. S., Zhu, R., Liu, Z., Lu, L., Peng, J., Tang, Z., ... Chan, W. K. (2016). Estimation of Hong Kong's solar energy potential using GIS and remote sensing technologies. Re-New. Energy, 99, 325-335. https://doi.org/10.1016/j.renene.2016.07.003

World Energy Outlook. (2018). International Energy Agency Website.

Yang, D., Kleissl, J., Gueymard, C. A., Pedro, H. T. C., \& Coimbra, C. F. M. (2018). History and trends in solar irradiance and PV power forecasting: A preliminary assessment and review using text mining. Sol. Energy, 168, 60-101. https://doi.org/10.1016/j.solener.2017.11.023

Yushchenko, A., de Bono, A., Chatenoux, B., Patel, M. K., \& Ray, N. (2018). GIS-based assessment of photovoltaic (PV) and concentrated solar power (CSP) generation potential in West Africa Renew. Sustain. Energy Rev., 81, 2088-2103. https://doi.org/10.1016/j.rser.2017.06.021

Zekai, S. (2014). Solar energy in progress and future research trends. Prog. Energy Combust. Sci., 30, 367-416. https://doi.org/10.1016/j.pecs.2004.02.004

\section{Copyrights}

Copyright for this article is retained by the author, with first publication rights granted to the journal.

This is an open-access article distributed under the terms and conditions of the Creative Commons Attribution license (http://creativecommons.org/licenses/by/4.0/). 